\title{
Using realistic trading strategies in an agent-based stock market model
}

\author{
Bàrbara Llacay ${ }^{\mathrm{a}, \mathrm{b}, 1}$, Gilbert Peffer ${ }^{\mathrm{a}, \mathrm{b}}$ \\ ${ }^{a}$ Centre Internacional de Mètodes Numèrics en Enginyeria (CIMNE), Campus Nord UPC, Gran Capità, \\ s/n, 08034 Barcelona, Spain \\ ${ }^{\mathrm{b}}$ Dept. for Economic, Financial, and Actuarial Mathematics, Faculty of Economics and Business, \\ University of Barcelona, Av. Diagonal 690, 08034 Barcelona, Spain.
}

\begin{abstract}
The use of agent-based models has increased in the last years to simulate social systems and, in particular, financial markets. Agent-based models of financial markets are usually validated by checking the ability of the model to reproduce a set of empirical stylised facts. However, other common-sense evidence is available which is often not taken into account, ending with models which are valid but not sensible. In this paper we present an agent-based model of a stock market which incorporates this type of commonsense evidence and implements realistic trading strategies based on practitioners literature. We next validate the model using a comprehensive approach consisting of four steps: assessment of face validity, sensitivity analysis, calibration and validation of model outputs.
\end{abstract}

Keywords: Agent-based simulation; validation; calibration; stylised facts; technical trading

JEL Classification: C63; G1; G20; G11

\section{Introduction}

\subsection{Background}

In recent times, an increasing effort has been devoted to building agent-based models (ABMs) of social systems and, in particular, of financial markets, as ABM is a flexible paradigm to study the individual and social behaviour of agents and its effect on the dynamics of the system. Many models of the stock market have been developed that focus on a broad range of market mechanisms and price dynamics ( (LeBaron, 2006), (Hommes, 2006), (Chakraborti, Toke, Patriarca, \& Abergel, 2011)). A usual way to validate these models is the analysis of their ability to replicate some of the statistical stylised facts identified in financial markets (Janssen \& Ostrom, 2006), such as the lack of return autocorrelation or the clustering of volatility.

However, other information about financial markets is available, such as the level of market volatility or the volumes moved by different types of agents, which can be used in the validation of an agent-based model but is often neglected in favour of the stylised facts. Even "common sense" evidence should be taken into account if possible without ignoring it only to achieve a

${ }^{1}$ Corresponding author at: Centre Internacional de Mètodes Numèrics en Enginyeria (CIMNE), Campus Nord UPC, Gran Capità, s/n, 08034 Barcelona, Spain. E-mail address: 1lacay@ cimne.upc.edu. Phone: +3493401 0795. Fax: +34934016517. 
more parsimonious model (Edmonds \& Moss, 2005). For this reason, we advocate in this article that it is also necessary to look at other basic empirical data, such as the volume moved by financial traders or their performance, to assess the validity of a model. If we only focus on the stylised facts reproduced by the model, we run the risk of having a model which is valid but not sensible.

It is precisely the problem we encountered when re-implementing a previous financial market model as a starting point of our research. We chose the model developed by Farmer and Joshi (2002) - henceforth, the 'FJ model' - because it is simple, a thorough analysis is provided by its authors, and it is able to reproduce a variety of empirical stylised facts. So, it is a valid model according to the usual criteria. However, when we looked at other model outputs, such as the performance of the different strategies, we found out that one of the trading strategies - the trend-following one - was systematically losing money. This situation would not make any sense in real markets, as a loss-making strategy would soon fall out of favour and ceased to be used. For this reason, we decided to enhance the model by re-designing the trend-following strategy. To this aim, we turned to the practitioners literature and implemented a realistic strategy based on a technical strategy widely used in real markets.

The model we present here makes a threefold contribution to the agent-based modelling literature: (1) we present the results of a model-to-model exercise where we have reimplemented the FJ model; (2) after reasoning that the results obtained from the FJ model do not satisfy certain common sense properties, we provide an enhanced model with a realistic technical trading strategy that builds on the practitioners literature; (3) we apply a four-step validation process to the new model which allows us to assess its validity in a more complete way than what is available in the related literature.

\subsection{Empirical validation of agent-based models}

Despite the potential of agent-based modelling, it has not been adopted yet as a mainstream tool by ortodox economists. One possible explanation draws on the lack of methodology standards in agent-based modelling, and an important aspect here is the diversity in calibration and validation procedures used by agent-based modellers (Fagiolo, Moneta, \& Windrum, 2007). The process of validation assesses how accurately a model or simulation represents the real world system in light of its objectives. Validation is preceded by the process of calibration, where model parameters are determined building on real world data. Calibration and validation are currently one of the most important challenges in agent-based modelling ( (Ngo \& See, 2012), (Bianchi, Cirillo, Gallegati, \& Vagliasindi, 2007)).

Beyond the difficulty of validation in general modelling and simulation (available resources are surveyed for example in (Balci, 1995) or (Sargent, 1998)), calibration and validation of agentbased models are specially challenging due to the inherent complexity of this type of models, where non-linearities, heterogeneity, stochastic dynamics, non-trivial interaction among agents and micro-macro feedback loops are usually present (Fagiolo, Windrum, \& Moneta, 2006). This has led to intensive discussions on how to validate agent-based models, as a result of which a variety of validation levels have been distinguished ( (Carley, 1996), (Bianchi, Cirillo, Gallegati, \& Vagliasindi, 2007)) and different validation methodologies have been proposed ( (Fagiolo, Moneta, \& Windrum, 2007), (Moss, 2008)) (specially remarkable here are the three empirical calibration and validation procedures surveyed by Windrum et al. (2007): the indirect 
calibration approach (Dosi, Fagiolo, \& Roventini, 2006), the Werker-Brenner approach (Werker \& Brenner, 2004) and the history-friendly approach (Malerba, Nelson, Orsenigo, \& Winter, 1999).

When reviewing the literature on model validation, the reader comes across a diversity of validation types - such as internal, external, conceptual or cross-model validation (Carley, 1996), which can be subsumed under the overall classification provided by Zeigler (1985):

- Replicative validity: the model outputs are compared to data already acquired from the real system.

- Predictive validity: the model is able to reproduce system behaviour before it is observed in the real system.

- Structural validity: the model "not only reproduces the observed real system behaviour, but truly reflects the way in which the real system operates to produce this behaviour." (Zeigler, 1985, p. 5)

One advantage of agent-based modelling is that it has the potential to replicate the microstructure and mechanisms that give rise to social phenomena under study and thus agentbased models can be structurally validated - which is the highest type of validity according to Zeigler.

Following Klügl (2008), structural validation can be decomposed in the following processes:

- Face validation: studies if initial model outcomes are plausible

- Sensitivity analysis: studies the effect of the model parameters on results. When implementing a large model, this allows to identify the crucial parameters.

- Calibration: identifies for which parameter values the model presents a better fit with real world.

- Output validation: studies whether model outputs match real-world data, usually through graphical or statistical comparison.

These processes are seldom wholly implemented in agent-based modelling (Ngo \& See, 2012) a fact that we will confirm in the next subsection in the particular case of ABM of financial markets. This paper makes a contribution to the ABM literature presenting a model of an artificial stock market fully validated by following these four steps to assess its structural validity. Our emphasis on the realistic modelling of agent strategies increases the structural validity of the model and moreover responds to the calls made by some researchers to adequately capture both the macro-level patterns and the micro-level behaviours and relationships (Gilbert, 2004) - this two-level validation is what Moss and Edmonds call crossvalidation (Moss \& Edmonds, 2005).

\subsection{Agent-based models of fundamentalist+technical traders}

In stock markets, two main investment approaches can be identified (Bonenkamp, 2010):

- Fundamentalist trading - Fundamentalist investors argue that assets have an intrinsic value, which can be determined with a detailed analysis of the characteristics of the asset, its issuer and the market (Murphy, 1999). The price is expected to move around 
the fundamental value, so when both diverge an investment opportunity appears: if the value exceeds the price the asset is said to be overvalued and it should be bought; if the value is lower than the price, then it should be sold (Malkiel, 1973).

- Technical analysis - This aproach builds on the analysis of past price movements to infere its future evolution. It claims that markets are driven by psychological factors which reflect investors' hopes and fears - rather than fundamentals (O'Neill, 2011). Technical analysis is much more recent than fundamentalist trading; its use largely spread since the $60 \mathrm{~s}$ and it has come to dominate the most modern and liquid markets (Johnson, Jefferies, \& Ming Hui, 2003).

Given that the main trading approaches in real markets are the fundamentalist and technical strategies, it makes sense to combine these two approaches when building a model of a financial market, to better resemble the behaviour of real investors ( (Menkhoff, 2010), (Moss \& Edmonds, 2005)). Many authors in the agent-based arena have also used stylised versions of the fundamentalist and the technical strategies to build models which are able to reproduce different statistical properties observed in real markets. For example, Farmer and Joshi (2002) study the role that these strategies have in market dynamics, LiCalzi and Pellizzari (2006) focus on the fundamentalist strategy, Wei et al. (2013) analyse the effect of momentum traders, and Raberto et al. (2003) use the Genoa Artificial Stock Market to study the profits made by these two main strategies. Some articles add features from the behavioural finance field to enrich the behaviour of agents: for example, the model by Pascual et al. (2006) includes psychological traders which are based on the research by Kahneman and Tversky (1979), and Shimokawa et al. (2007) also build on the work by Kahneman and Tversky and study the effect of risk aversion. Other models focus on the impact of learning algorithms: the traders in the Santa Fe Stock Market ( (Arthur, Holland, LeBaron, Palmer, \& Tayler, 1996), (LeBaron, Arthur, \& Palmer, 1999)) use a genetic algorithm to update their price prediction rules, and Martínez-Jaramillo and Tsang (2009) also explore different procedures to update the decision rules of artificial traders. Finally, a number of articles focus on the effect of imitation mechanisms, allowing the agents to improve their strategies by looking at other agents, or adopting the main strategy in the market ( (LeBaron \& Yamamoto, 2007), (Alfarano, Lux, \& Wagner, 2005), (Lux \& Marchesi, 1999) or (Westerhoff, 2010)).

Also building on these two trading approaches, we implement a model with two types of investors: fundamentalist traders (FUND) and technical traders (TREND). Our model makes a contribution to the previous literature in two aspects: (1) implementation of realistic trading strategies based on practitioners literature, and (2) complete assessment of the model structural validity. Building on the FJ model mentioned above (Farmer \& Joshi, 2002), we will modify the technical strategy to avoid certain features that run counter to common sense evidence, and for that aim we will turn to the practical trading literature to implement a sound, realist strategy for technical investors. Next, we will assess the validity of the model following the four-step procedure proposed by Klügl (2008).

The financial market models reviewed above are cross-validated (Moss \& Edmonds, 2005), as they all compare the statistical properties of the simulated time series with the stylised facts observed in real markets - so a macro-level validation is applied -, and the agent strategies inspire on the most popular trading approaches in real world - so the micro level is informed by the behaviour of real traders. This two-level validation is an improvement on the models one can find in other fields. However, if we turn to the four-step validation procedure proposed by 
Klügl (2008), we realise that some processes are usually missing. Table 1 summarises which validation steps are addressed in the models reviewed above, and it becomes clear that although the outputs are always validated, no sensitivity analysis is usually undertaken, and calibration is also a weak point of some models. In contrast to this, we have applied the complete validation procedure to our model, as described later.

\begin{tabular}{|c|c|c|c|c|}
\hline Model & $\begin{array}{c}\text { Face } \\
\text { validation }\end{array}$ & $\begin{array}{l}\text { Sensitivity } \\
\text { analysis }\end{array}$ & Calibration & $\begin{array}{c}\text { Output } \\
\text { validation }\end{array}$ \\
\hline Alfarano, Lux and Wagner (2005) & O & & $\bullet$ & $\bullet$ \\
\hline Arthur et al. (1996) & O & & O & $\bullet$ \\
\hline Farmer and Joshi (2002) & $\bullet$ & & O & $\bullet$ \\
\hline $\begin{array}{l}\text { LeBaron, Arthur and Palmer } \\
\text { (1999) }\end{array}$ & O & O & O & $\bullet$ \\
\hline LeBaron and Yamamoto (2007) & & & & $\bullet$ \\
\hline LiCalzi and Pellizzari (2002) & & O & & $\bullet$ \\
\hline Lux and Marchesi (1999) & O & & & $\bullet$ \\
\hline $\begin{array}{l}\text { Martínez-Jaramillo and Tsang } \\
\text { (2009) }\end{array}$ & O & O & O & $\bullet$ \\
\hline Pascual et al. (2006) & & & & $\bullet$ \\
\hline Raberto et al. (2003) & O & & O & $\bullet$ \\
\hline Shimokawa et al. (2007) & O & & & $\bullet$ \\
\hline Wei et al. (2013) & O & & $\bullet$ & $\bullet$ \\
\hline Westerhoff (2010) & 0 & & 0 & $\bullet$ \\
\hline
\end{tabular}

Table 1 - Validation steps used in agent-based models of fundamentalist+technical traders, following Klügl (2008). A dark circle indicates that the step is fully satisfied; a blank circle indicates that the step is partially addressed; no circle indicates that the validation step is not addressed at all.

In section 2 we present our agent-based model and describe how we have implemented both trading strategies, founding on empirical usual practice. In section 3 we describe the validation procedure, consisting of four steps: assessment of face validity, sensitivity analysis, calibration and output validation. Section 4 then concludes our discussion. 


\section{Model description}

\subsection{Starting point: Reimplementation of FJ model}

One methodological issue in agent-based modelling is the high diversity in model objectives, structure and theoretical context that hinders the comparison between developed models (Fagiolo, Windrum, \& Moneta, 2006). For this reason, the comparison of models has been advocated as a way to increase the credibility and the validity of a model (North \& Macal, 2007).

Following the model-to-model approach (Hales, Rouchier, \& Edmonds, 2003), we decided to build on a previous financial market model instead of developing yet another model from scratch. This incremental procedure is in line with the TAPAS (Take A Previous model and Add Something) approach, which improves the validity of new models by building on existing, tested, well-understood and accepted models (Frenken, 2005). In particular, we chose the FJ model as it is simple but able to reproduce different empirical stylised facts, a good description is available and a deep analysis is provided by its authors.

Due to space limitations, we do not include here any detailed description of the FJ model, but only a brief summary. For further details, we refer the reader to the original paper.

Two types of traders are considered:

- Value investors, who take positions proportional to the difference between the price and their perception of the fundamental value, in the belief that the price will tend to the value.

- Trend-following investors, who take positions proportional to the difference between the current and a past price, in the belief that prices move in trends.

Both types of agents use thresholds to enter and exit a position, what can be understood as a way to reduce the trading frequency motivated by excessive transaction costs. The net order submitted by all traders is filled by a market maker that sets the new price.

The model exhibits face validity, as the time series of simulated prices show a qualitative correspondence to the real series of prices. The statistical analysis of results reveals that the model replicates different empirical stylised facts - fat tails of log-return distribution, volume skewness, strong autocorrelation of volume and volatility - so outputs are validated. 
QQ plot of log-returns

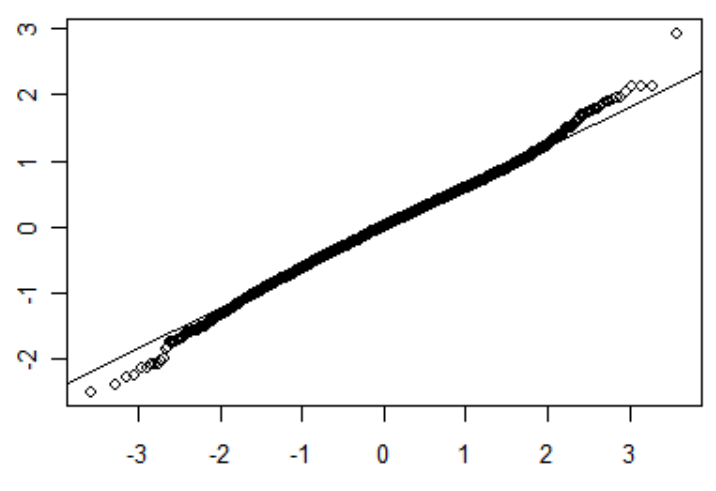

ACF of volume

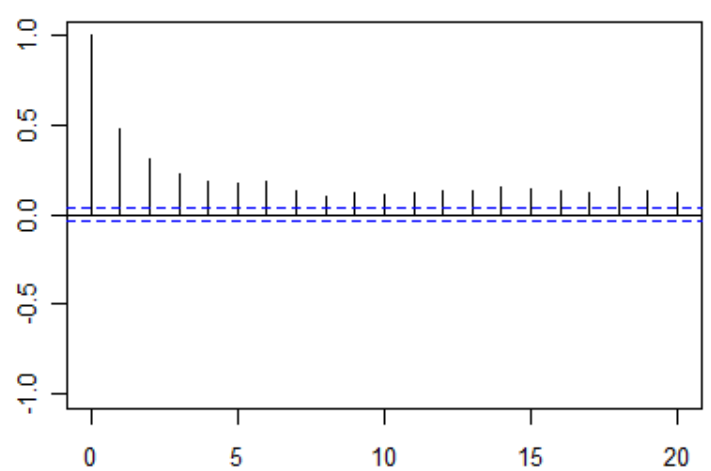

Histogram of volume
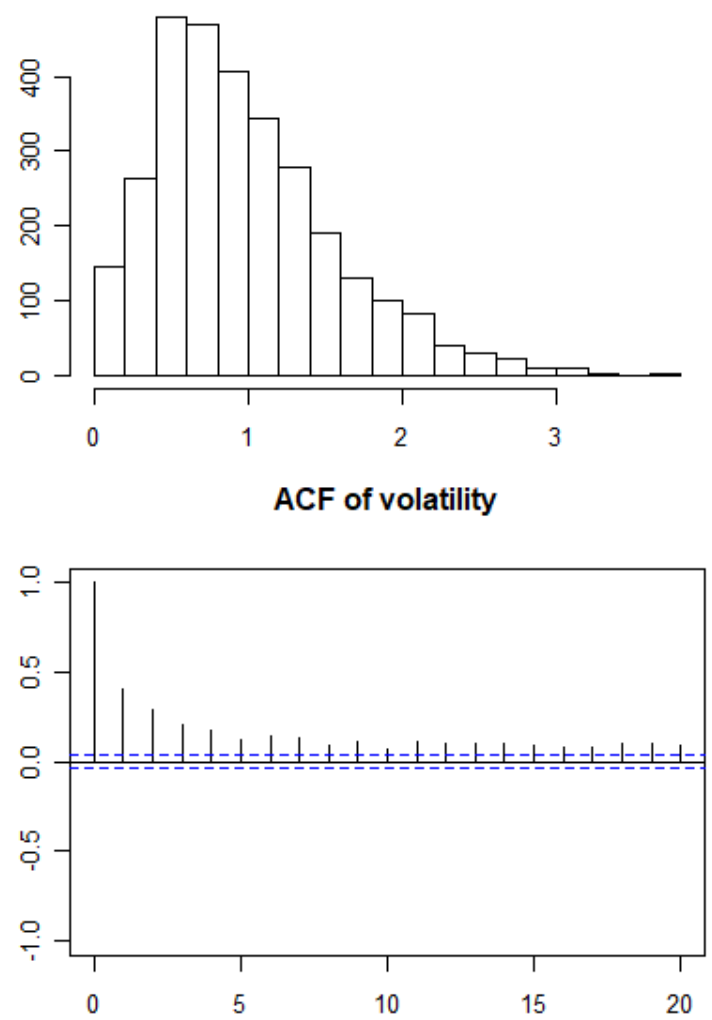

Figure 1 - Illustration of statistical facts obtained in the replication of the FJ model, using the same type of plots than displayed in the paper by Farmer and Joshi for better comparability. Upper left: Q-Q plot of return distribution. Upper right: Histogram of volume distribution. Lower left: Autocorrelation function of volume. Lower right: Autocorrelation function of volatility as absolute returns

In our reimplementation of the FJ model we not only looked at the results reported in the paper by Farmer and Joshi - Figure 1 reproduces the statistical analyses displayed in the FJ paper using our own data to assess the correctness of the reimplementation exercise, - but took a deep exploration of other variables and features, such as agent orders, positions or performance. Figure 2 provides a summary of market dynamics, and brings to light a particular fact that attracted our attention: trend traders get negative profits. This is a recurring feature, robust under different parameter configurations. This situation is clearly not realistic, as a systematically loss-making strategy would soon disappear from real markets. 

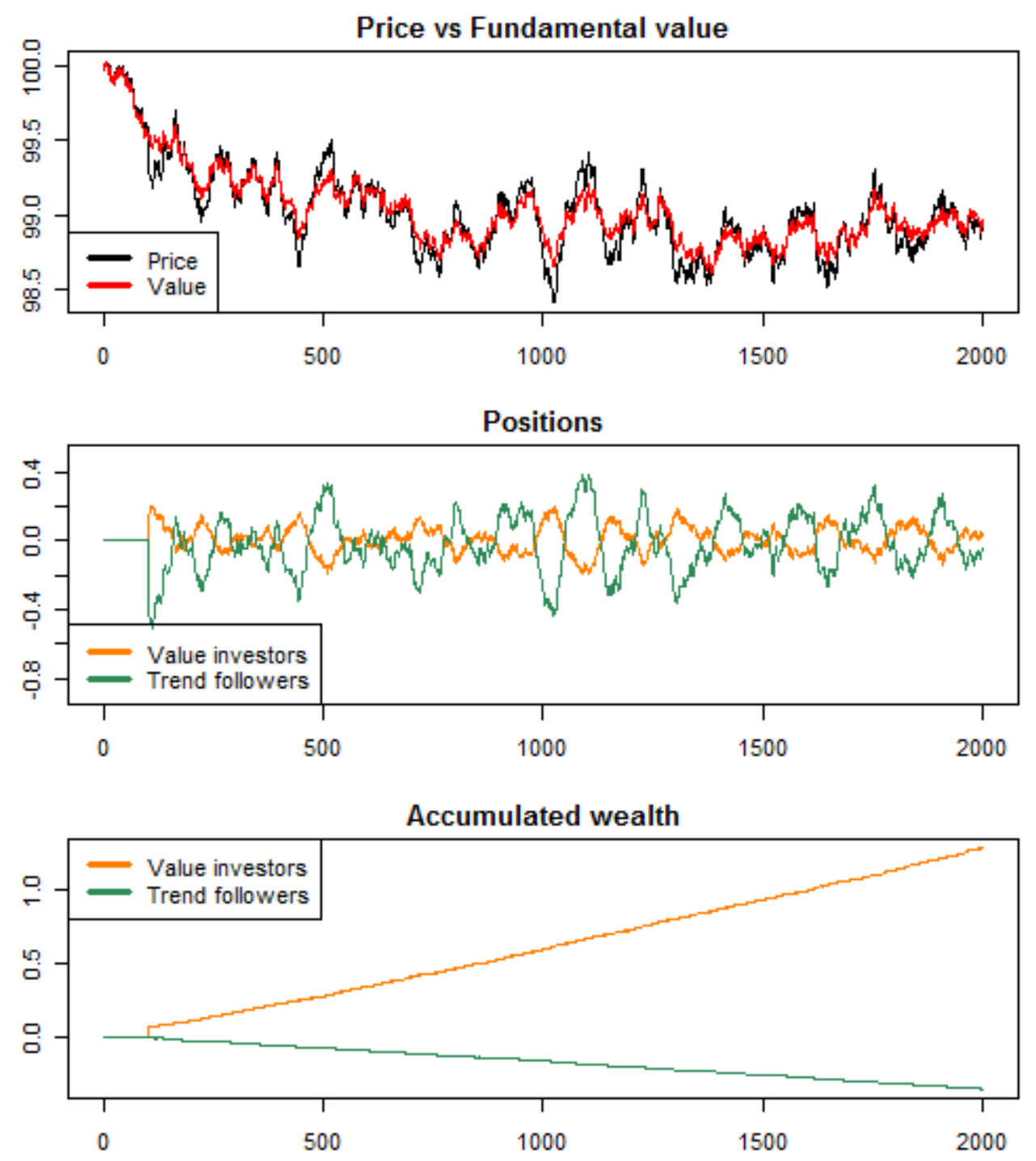

Figure 2 - Illustration of market dynamics obtained in the replication of the FJ model

This type of stylised fact is perhaps so blatantly obvious that one may fail to even take it into account. With the present paper we want to point at the need to incorporate this type of common-sense evidence into agent-based models. With this aim in mind, we decided to enhance the FJ model by implementing a realistic technical strategy that is competitive against the fundamentalist strategy while keeping the many virtues of the FJ model. We describe next the several model components, where the price formation process and the fundamentalist strategy build on the FJ paper, and the technical strategy builds on the practitioners literature.

\subsection{Model description}

We consider a market for multiple assets - stocks - in unrestricted supply, where traders - who have no cash nor short-selling constraints - place orders at discrete trading intervals, changing the composition of their investment portfolios in accordance with their respective valuation 
model. At each time step, all the agents trade in random order, and a new price is set based on the aggregated order submitted by traders ${ }^{2}$.

\subsubsection{Price formation}

The price $P_{t}$ for the stock is set by a market maker in accordance to a linear price formation rule. Although other formulations are possible (see e.g. (Madhavan, 2000) for a survey), we use the simplest one, which states that prices have to rise (fall) in the presence of over-demand (oversupply) by an amount that is inversely proportional to the liquidity of the traded security. Here, we do not take into account the inventory of the market maker nor the presence of information asymmetries in the market, and thus assume bid-ask spreads to be zero. Stock price is updated according to:

$$
P_{t}=P_{t-1}+\frac{1}{\lambda} \cdot \Theta_{t-1}+\xi_{t},
$$

where

- $\Theta_{t-1}$ is the total excess order, that is the sum of all orders emitted in $t-1$

- $\lambda$ is a constant liquidity factor that accounts for the depth of the market

- $\xi_{t}$ is a random term, $\xi_{t} \sim N\left(0, \sigma_{P}\right)$, that accounts for the random perturbations - such as the arrival of new information - that can possibly affect the market-maker's decision making process.

One disadvantage of this linear formulation is that prices can become negative, which could be avoided by using a log-price formulation for the price discovery rule. Outstanding orders in any given trading interval are always filled at the quoted prices and the market maker absorbs the excess or covers the shortfall, adjusting the prices according to the impact function ( 1 ).

\subsubsection{Fundamentalist traders (FUND)}

Our implementation of the fundamentalist strategy is based on the FJ model. Fundamentalist investors derive the intrinsic value of the stock from a private, exogenous signal they receive before each trading period. This exogenous signal is modelled as a random walk $V_{t}$, plus an agent-specific constant $v^{f}$ that accounts for the variability in the perception of the fundamental value:

$$
V_{t}^{f}=V_{t}+v^{f}, \text { where } V_{t}=V_{t-1}+\eta_{t},
$$

where $\eta_{t}$ is drawn from a normal distribution with constant variance, $\eta_{t} \sim N\left(0, \sigma_{V}\right)$, and the agent-specific constant $v^{f}$ is set at the start of the simulation from a uniform distribution, $v^{f} \sim U\left(v_{\min }, v_{\max }\right)$, with $v_{\min }=-v_{\max }$.

The positions of fundamentalist traders are proportional to the difference of actual price $P_{t}$ to perceived fundamental value $V_{t}^{f}$. However, an agent only enters a position when the difference between price and value is above a given threshold, $\left|V_{t}^{f}-P_{t}\right|>T^{f}$. In that case, the position is determined as:

\footnotetext{
${ }^{2}$ Code is available at https://libraries.io/github/gitwitcho/var-agent-model. Our code is implemented in Java and uses the scheduler from Repast simphony (https://repast.github.io/repast_simphony.html)
} 


$$
\operatorname{pos}_{t}^{f}=V_{t}^{f}-P_{t} .
$$

Let's note that when the price lies above the fundamental value, the asset is overpriced and the agent decides to sell; when the price lies below the fundamental value, then the agent decides to buy.

Fundamentalist investors keep their positions open until the price and the fundamental value converge, that is, until their difference is smaller than a given threshold. In that case, the agents liquidate their position:

$$
\begin{aligned}
& \text { If } \operatorname{pos}_{t-1}^{f}>0 \& V_{t}^{f}-P_{t}^{f}<\tau^{f} \text { then } \operatorname{pos}_{t}^{f}=0 . \\
& \text { If } \operatorname{pos}_{t-1}^{f}<0 \& V_{t}^{f}-P_{t}^{f}>-\tau^{f} \text { then } \operatorname{pos}_{t}^{f}=0 .
\end{aligned}
$$

In case an agent has an open position, but the liquidation condition is not satisfied, then it simply updates its position based on the difference between price and value: if this difference has reduced (widened) since the position was opened, then the investor also reduces (increments) its position:

$$
\operatorname{pos}_{t}^{f}=V_{t}^{f}-P_{t} \text {. }
$$

Fundamentalist investors are heterogeneous in their entry and exit thresholds:

$$
T^{f} \sim U\left(T_{\min }, T_{\max }\right), \quad \tau^{f} \sim U\left(\tau_{\min }, \tau_{\max }\right) .
$$

Once determined the new position, the agent calculates the order to be sent to the market-maker:

$$
\theta_{t}^{f}=\operatorname{pos}_{t}^{f}-\operatorname{pos}_{t-1}^{f} .
$$

Figure 3 summarises how the fundamentalist strategy works:

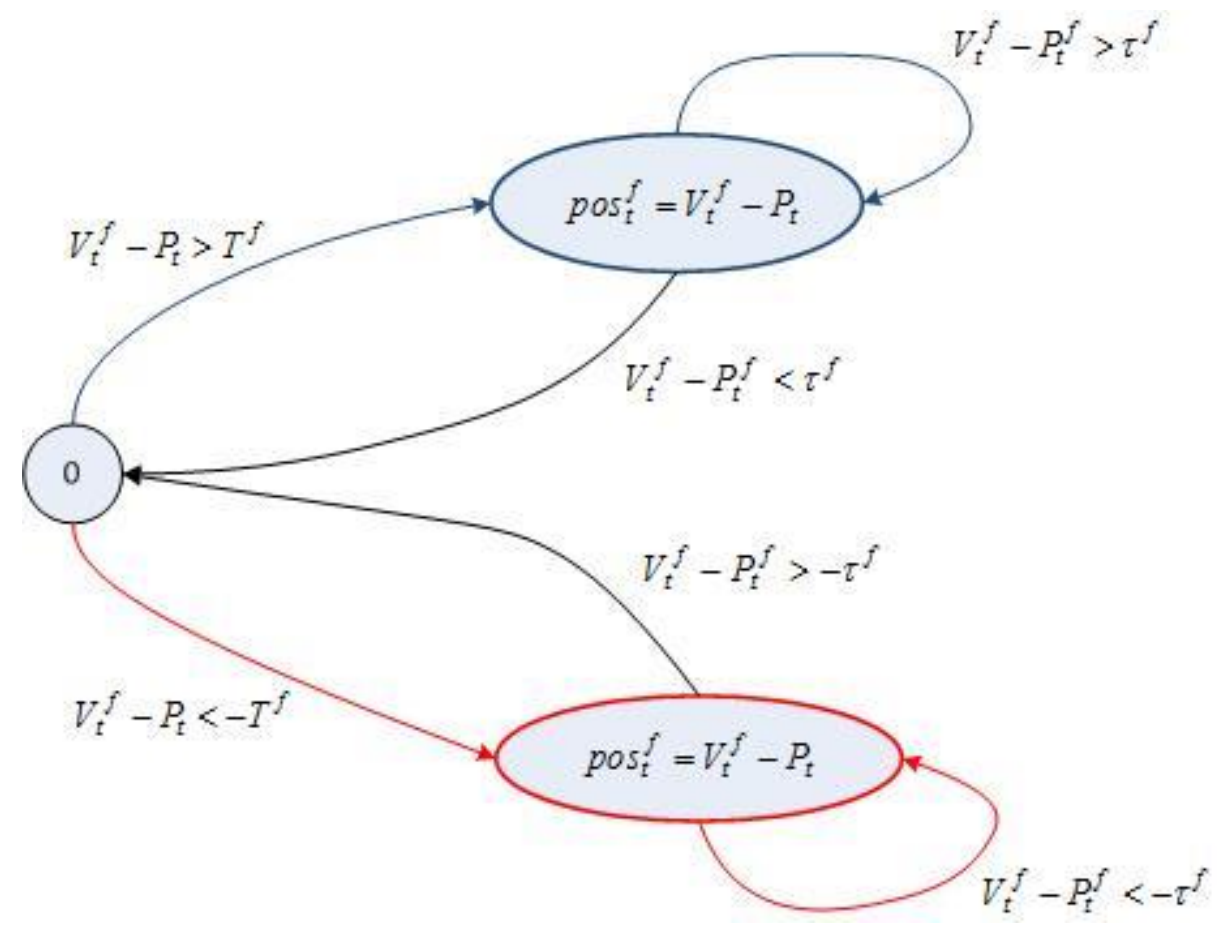


Figure 3 - State diagram of the fundamentalist strategy

\subsubsection{Technical traders (TREND)}

Technical traders exploit price trends, and for that aim we have implemented two of the most common techniques in real markets (Taylor S. , 2005): to detect the start of a trend in prices, agents compare a short- and a long-term moving average of past prices; to detect the end of a price trend, agents rely on the technique of channel breakouts. To implement these rules, we have built on the practitioner literature, mainly on the description provided in (Kestner, 2003).

At each time step, technical investors calculate two simple moving averages (MA) of past prices: one short-term MA that responds quickly to recent price movements, and a long-term MA that responds more slowly. Let $w_{S}^{t r}$ and $w_{L}^{t r}$ be the windows used by the technical agent $t r$ to calculate his short- and long-term moving averages, respectively. The moving averages are then given by:

$$
\begin{aligned}
& M A\left(w_{S}^{t r}\right)_{t}=\frac{1}{w_{S}^{t r}} \cdot \sum_{i=t-w_{S}^{t r}+1}^{t} P_{i} \\
& M A\left(w_{L}^{t r}\right)_{t}=\frac{1}{w_{L}^{t r}} \cdot \sum_{i=t-w_{L}^{t r}+1}^{t} P_{i}
\end{aligned}
$$

When the two moving averages cross, it is the key time to buy or sell: if the short-term MA crosses the long-term MA from below, the agent interprets it as the beginning of an upward trend and opens a long position; if the short-term MA crosses the long-term MA from above, the agent interprets it as the start of a downward trend and opens a short position (Figure 4).

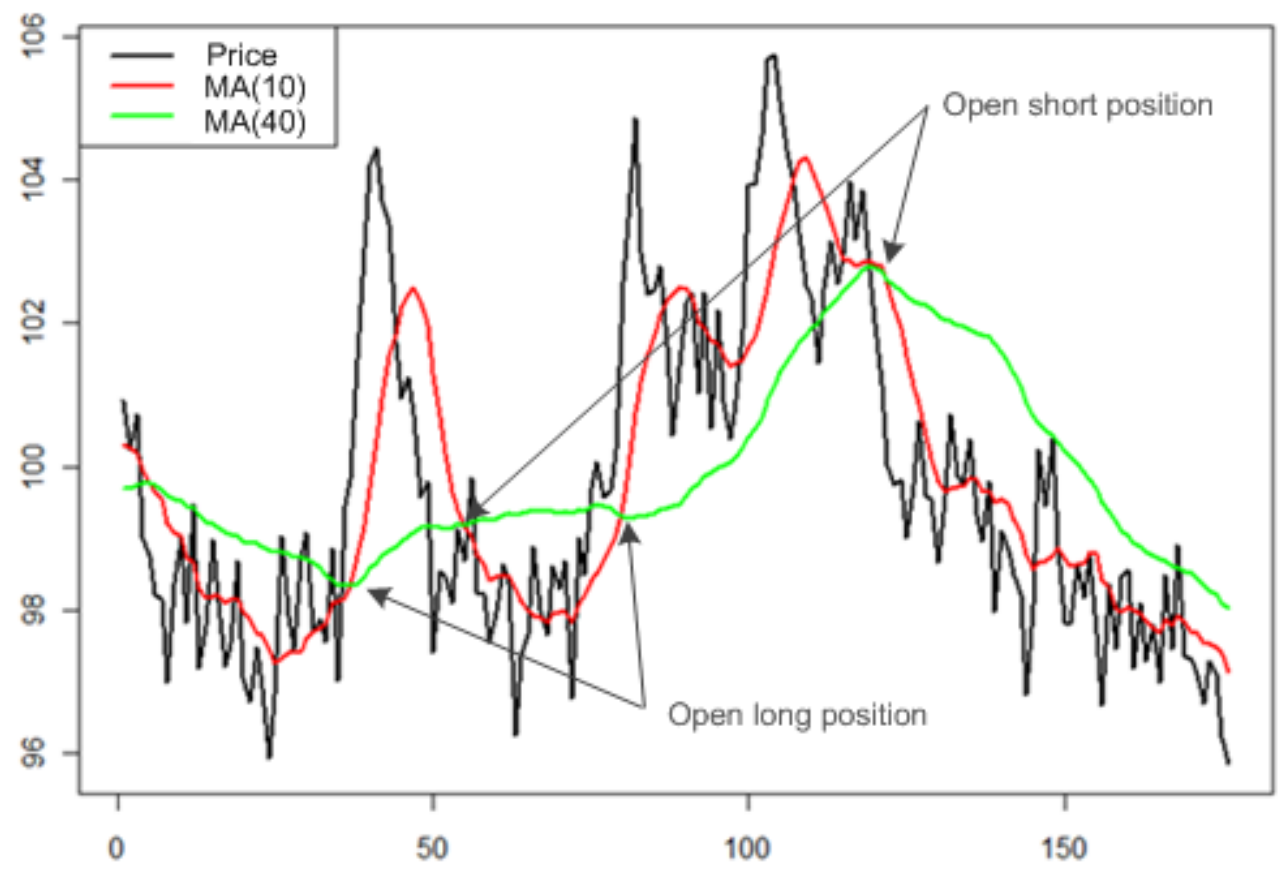

Figure 4 - Illustration of the behaviour of long- and short-term moving averages along time 
When the MA's cross and the agent opens a position, it is proportional to the difference in slope between the two moving averages, because it is assumed that the greater this difference, the steeper the upward or downward price trend. Equations ( 8 ) and ( 9 ) specify the formula used by technical investors to calculate their position:

- If $M A\left(w_{S}^{t r}\right)_{t}$ crosses $M A\left(w_{L}^{t r}\right)_{t}$ from below, then the agent opens a long position:

$$
\operatorname{pos}_{t}^{t r}=25 \cdot\left|\Delta i n c l_{t}^{t r}\right|
$$

- If $M A\left(w_{S}^{t r}\right)_{t}$ crosses $M A\left(w_{L}^{t r}\right)_{t}$ from above, then the agent opens a short position:

$$
\operatorname{pos}_{t}^{t r}=-25 \cdot\left|\Delta i n c l_{t}^{t r}\right|
$$

where

- 25 is a normalisation factor aimed at having the same order of magnitude in the orders from fundamentalist and technical agents ${ }^{3}$.

- $\Delta i n c l_{t}^{t r}$ is the difference between the slope of the two MA's:

$$
\Delta i n c l_{t}^{t r}=\arctan \left(M A\left(w_{S}^{t r}\right)_{t}-M A\left(w_{S}^{t r}\right)_{t-1}\right)-\arctan \left(M A\left(w_{L}^{t r}\right)_{t}-M A\left(w_{L}^{t r}\right)_{t-1}\right)
$$

Technical investors keep their positions open until they think that the price trend has begun to reverse. In order to detect a trend reversal, the agents use a channel breakout rule: if the current price is the lowest in the last $w_{C}^{t r}$ days, then the technical trader interprets that the price is going down, and any long position should be liquidated; if the current price is the highest in the last $w_{C}^{t r}$ days, then the technical trader interprets that the price is going up, and any short position should be liquidated.

$$
\begin{aligned}
& \text { If } \operatorname{pos}_{t-1}^{t r}>0 \& P_{t}=\underset{j \in\left[t-w_{C}^{t r}+1, t\right]}{\operatorname{Min}}\left\{P_{j}\right\} \text { then } \operatorname{pos}_{t}^{t r}=0 . \\
& \text { If } \operatorname{pos}_{t-1}^{t r}<0 \& P_{t}=\underset{j \in\left[t-w_{C}^{t r}+1, t\right]}{\operatorname{Max}}\left\{P_{j}\right\} \text { then } \operatorname{pos}_{t}^{t r}=0 .
\end{aligned}
$$

Note that when drawing the minimum and the maximum of the price over a period, a channel appears, which is why the method is called "channel breakout" (Figure 5).

As happens with the fundamentalist investors, when a technical agent has an open position, but the channel breakout condition is not satisfied, then he simply updates his position keeping the same sign:

$$
\text { If } \operatorname{pos}_{t-1}^{t r}>0 \text { then } \operatorname{pos}_{t}^{t r}=25 \cdot \mid \Delta \text { incl }_{t}^{t r} \mid
$$

\footnotetext{
${ }^{3}$ As the fundamentalist and technical agents use quite different indicators for their positions - one based on the difference between price and fundamental value, and the other one based on the difference of slope between moving averages - the model runs the risk of having one group of traders moving far major volumes and biasing the market dynamics. To give fundamentalist and technical agents the a priori opportunity to impact prices in a balanced way, we have added this normalisation factor. To calculate it, we have repeatedly run the model and calculated the ratio of average maximum fundamentalist and technical positions obtained after each run. The normalisation factor has been selected as the value for which the ratio of maximum fundamentalist/technical positions lies around 1, as this indicates that fundamentalist and technical positions take similar values and so both groups of traders have a priori a similar impact in price formation.
} 


$$
\text { If } \operatorname{pos}_{t-1}^{t r}<0 \text { then } \operatorname{pos}_{t}^{t r}=-25 \cdot\left|\Delta i n c l_{t}^{t r}\right| \text {. }
$$

Technical investors are heterogeneous in the windows of the moving averages and breakout channel:

$$
w_{S}^{t r} \sim U\left(w_{S, \text { min }}^{t r}, w_{S, \text { max }}^{t r}\right), \quad w_{L}^{t r} \sim U\left(w_{L, \text { min }}^{t r}, w_{L, \text { max }}^{t r}\right), \quad w_{C}^{t r} \sim U\left(w_{C, \min }^{t r}, w_{C, \max }^{t r}\right) .
$$

Once set the new position, the agent calculates the order to be sent to the market-maker:

$$
\theta_{t}^{t r}=\operatorname{pos}_{t}^{t r}-\operatorname{pos}_{t-1}^{t r}
$$

Figure 6 summarises how the technical strategy works:

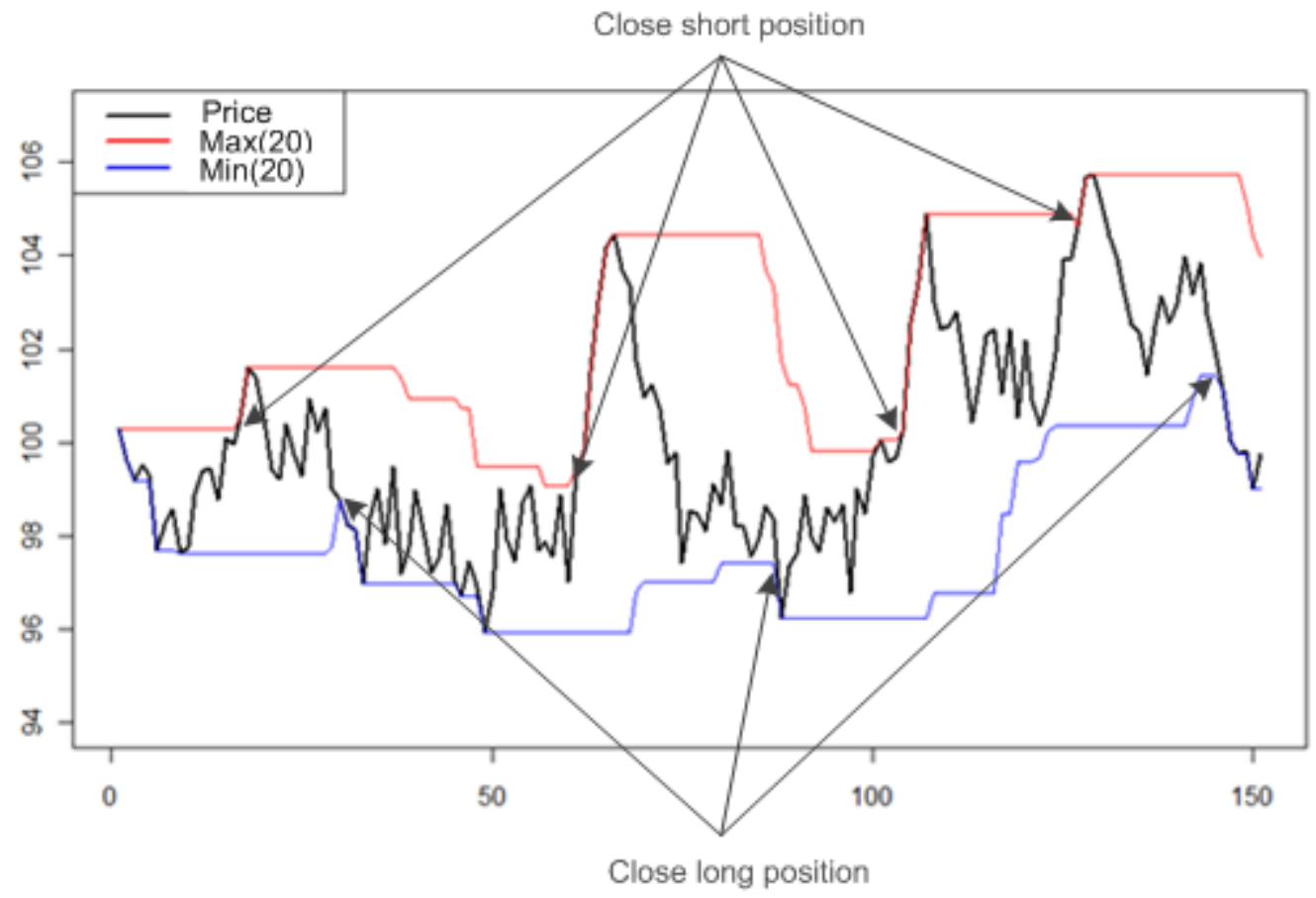

Figure 5 - Illustration of the behaviour of the channel used as exit condition 


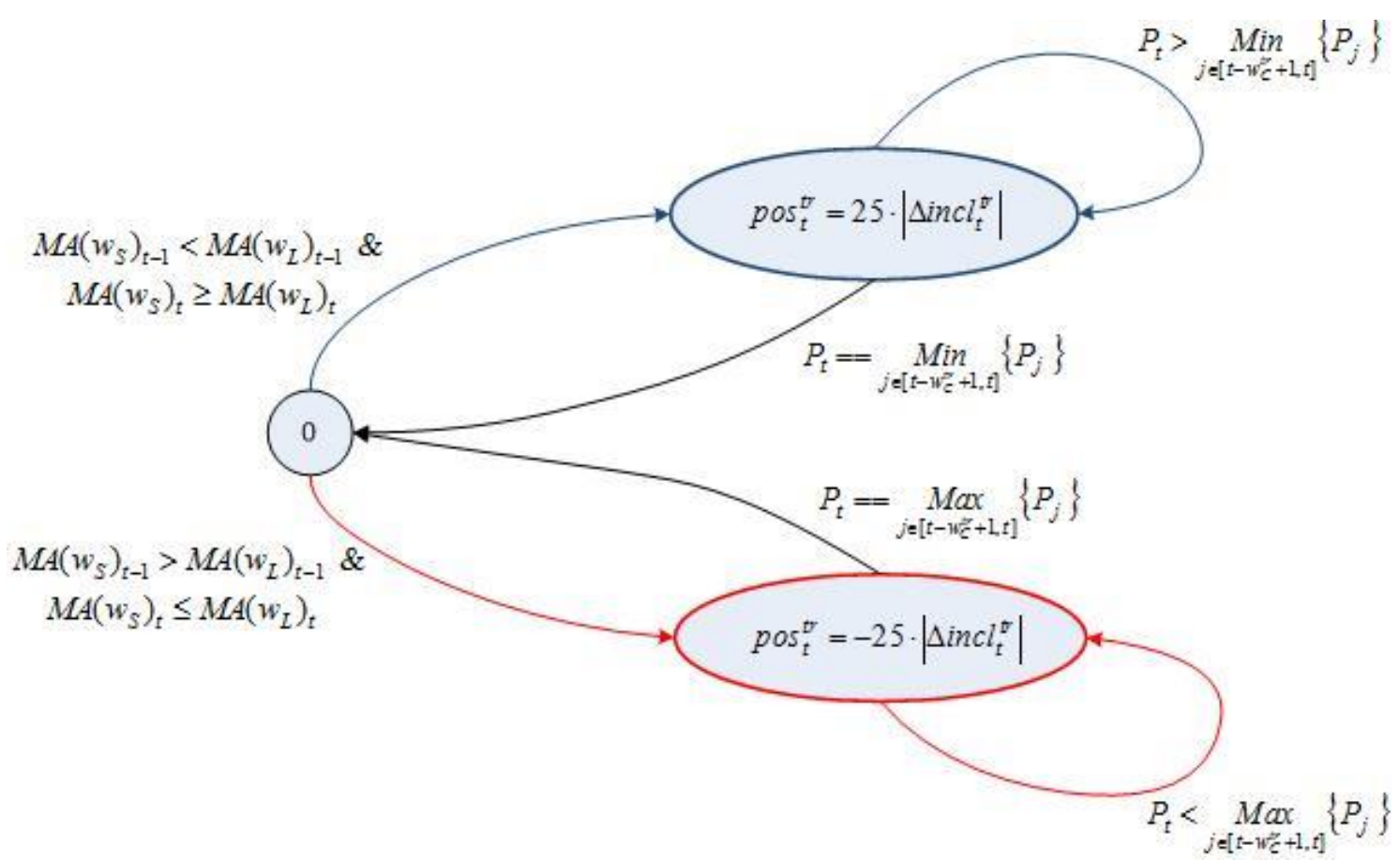

Figure 6 - State diagram of the technical strategy

\section{Description of model validation}

We describe next the validation procedure used to assess the validity of the model described in section 2. Although the four steps are presented in a linear way, it is rather an iterative process, with movements back and forth between the different steps. For example, a temptative calibration can be done before conducting the sensitivity analysis, or calibration is often undertaken with the aim of replicating the sylised facts used later in the validation of outcomes.

In all the graphics shown throughout this section, we have used the parameter values listed in Table 2, unless otherwise indicated. All simulations have a duration of 2000 time steps (we assume that each time step is equivalent to 1 day, and so each run has an equivalent duration of 8 years). Average results shown next are based on 200 runs with different seeds for random processes.

\subsection{Face validation}

In this section we will look at different variables to understand how the model works and which types of results are produced.

Price and fundamental value. The price moves around the fundamental value. While it may be that the price and fundamental value do not cross for a long time period, they end up converging due to the action of traders (Figure 7). The action of fundamentalist investors prevents the price from going too far away from the fundamental value, since when the price falls below the value, fundamentalist agents buy and push the price up, and vice versa. Technical investors propel the trends in price: when the price begins to increase, they buy and strengthen the price rise 
(analogously when the price begins to drop). The joint action of fundamentalist and technical investors cause the price trends to be temporary, and the price always ends up moving around the fundamental value. Therefore, the price has a stable dynamic and shows no bubbles nor crashes.

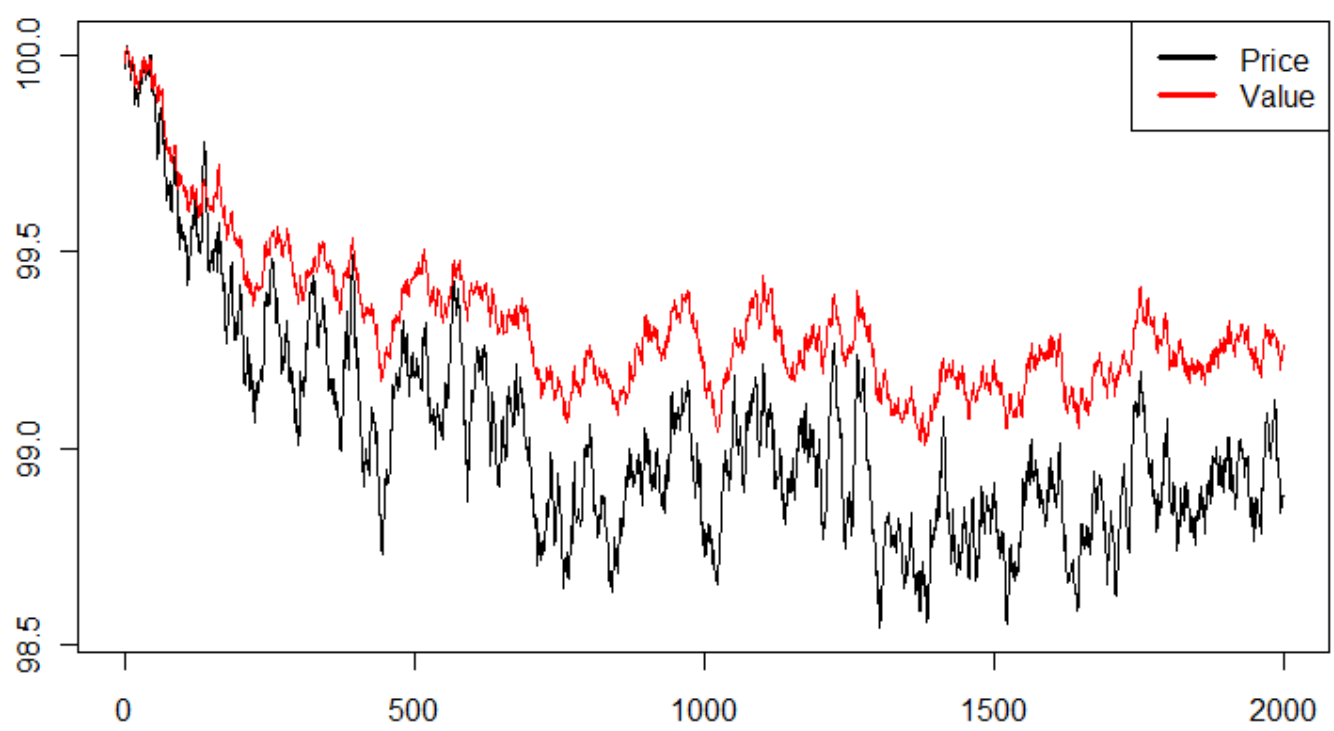

Figure 7 - Average of price and fundamental value over 200 runs

Figure 8 shows the time series of annualised volatility, which does not show important variations during the course of the simulation. Note that the level of volatility is reasonably close to the empirical volatility observed in stock markets during calm periods (for example, the average volatility of S\&P500 during 2014 was 11\%).

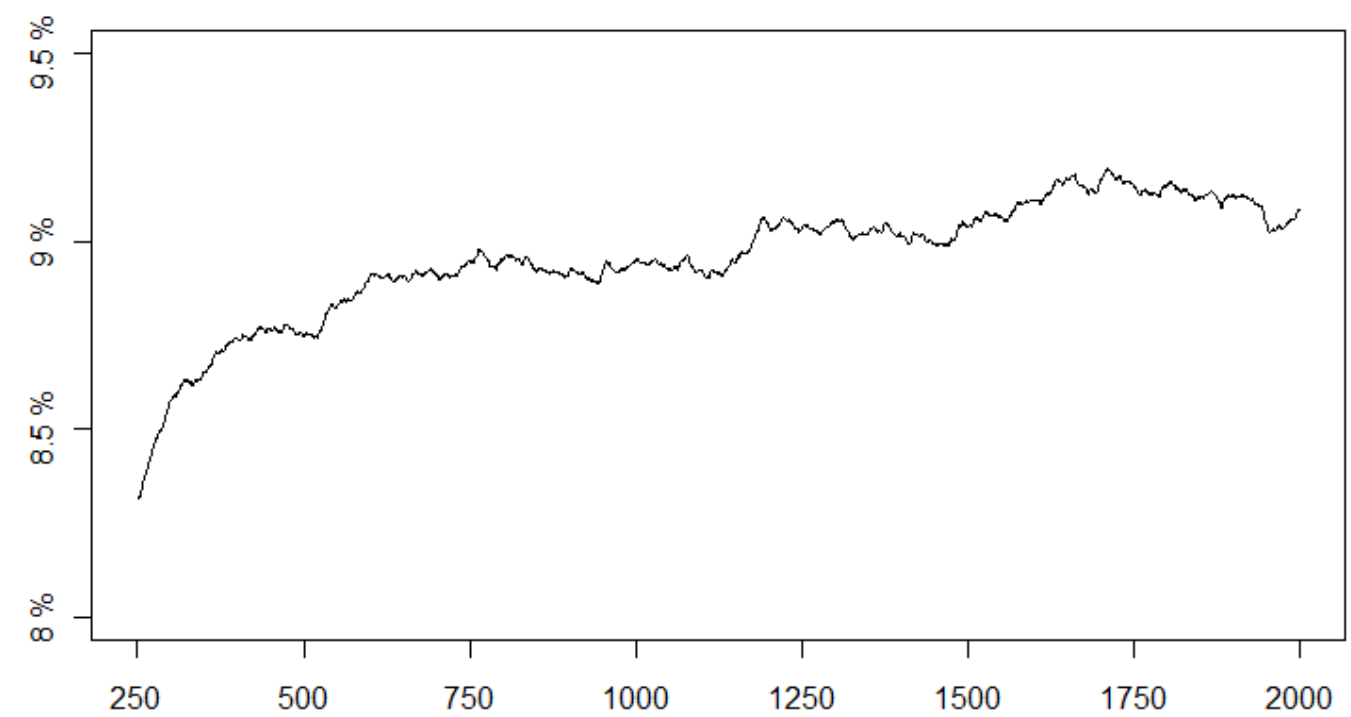

Figure 8 - Average volatility of returns over 200 runs

Orders from investors. By construction, the positions of fundamentalist and technical investors have the same order of magnitude (precisely we have added a normalisation factor to the 
expression of technical positions to prevent a group from having far superior positions than the other group, see equations ( 8 ) and ( 9 )).

\section{FUND}

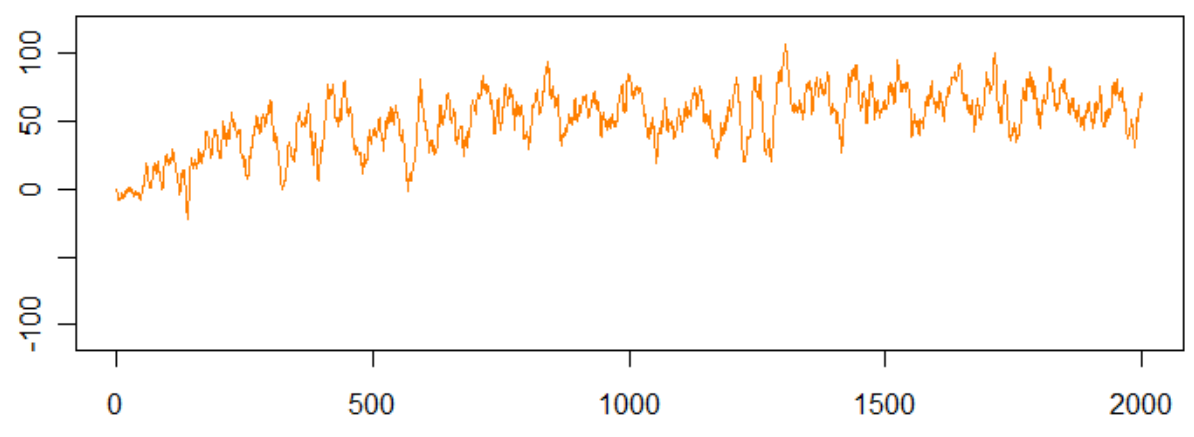

TREND

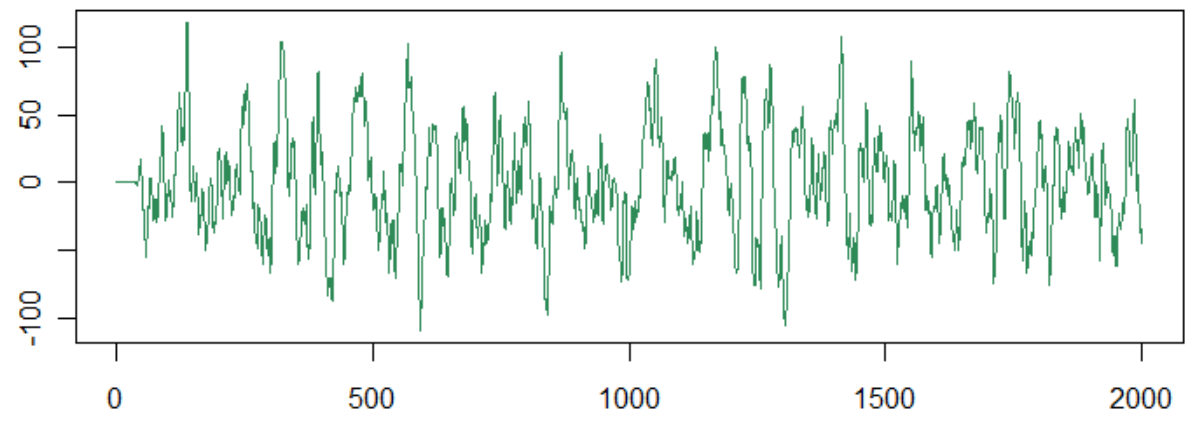

Figure 9 - Average positions of fundamentalist and technical investors over 200 runs

Note that the aggregate positions of technical investors usually move in the direction of prices if the price rises, technical investors buy - whereas the aggregate positions of fundamentalist investors tend to move in the opposite direction - if the price rises and exceeds the fundamental value, fundamentalist investors sell (hence the technical investors induce a positive autocorrelation in returns, and fundamentalist investors induce a negative autocorrelation). This can be clearly seen when doing a zoom in the graphic of price and aggregate positions of agents: 


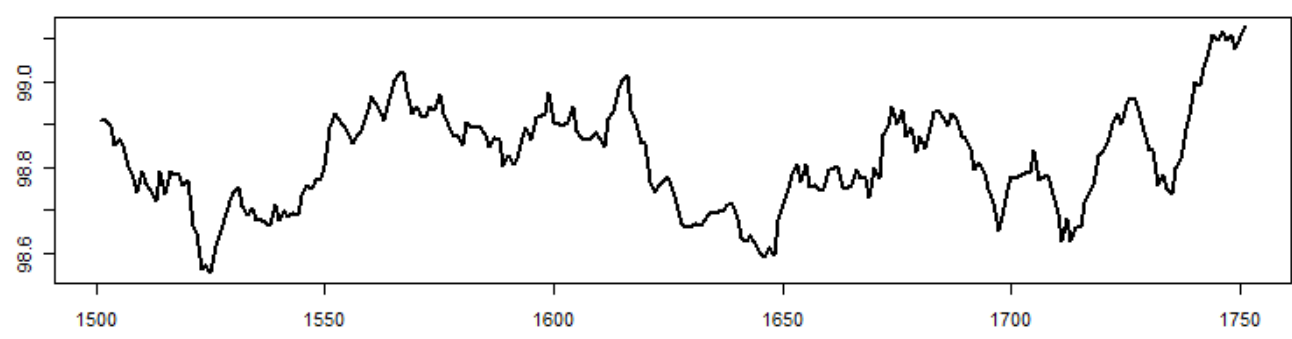

FUND positions

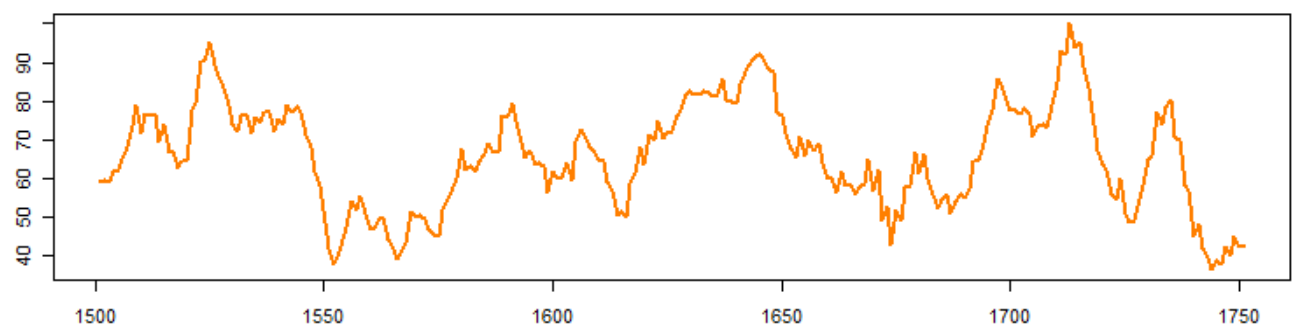

TREND positions

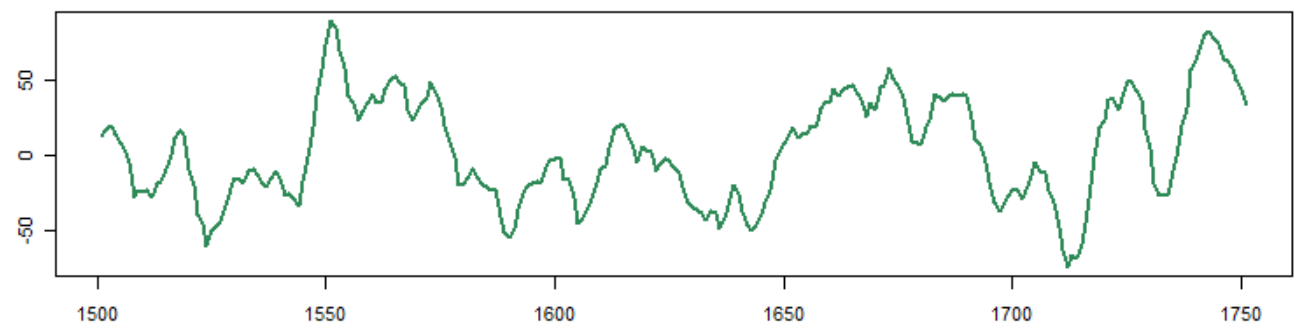

Figure $10-$ Zoom for $\mathrm{t}=1500 . .1750$ of the average of price and aggregate positions of fundamentalist and technical investors over 200 runs

In Figure 9 we can see that the positions of technical investors suffer higher variations than those of fundamentalist investors, because when the trend in the price reverts, technical investors liquidate their portfolio and pass from long to short positions (or vice versa), while fundamentalist agents do not necessarily liquidate their portfolio because the difference between the price and the fundamental value does not need to change sign. The fact that the positions of technical traders suffer higher changes between two time steps translates into higher orders (see Figure 11), and so the impact of the technical group in price formation is more noticeable. This is consistent with the volume patterns observed in real world: although there is no data on which volume is moved by fundamentalist and technical investors in real markets, there is indeed evidence that most mutual funds behave as technical investors in short-term trades (Menkhoff, 2010), and technical strategies have a higher weight in stock price dynamics (Feng, Li, Podobnik, Preis, \& Stanley, 2012). 


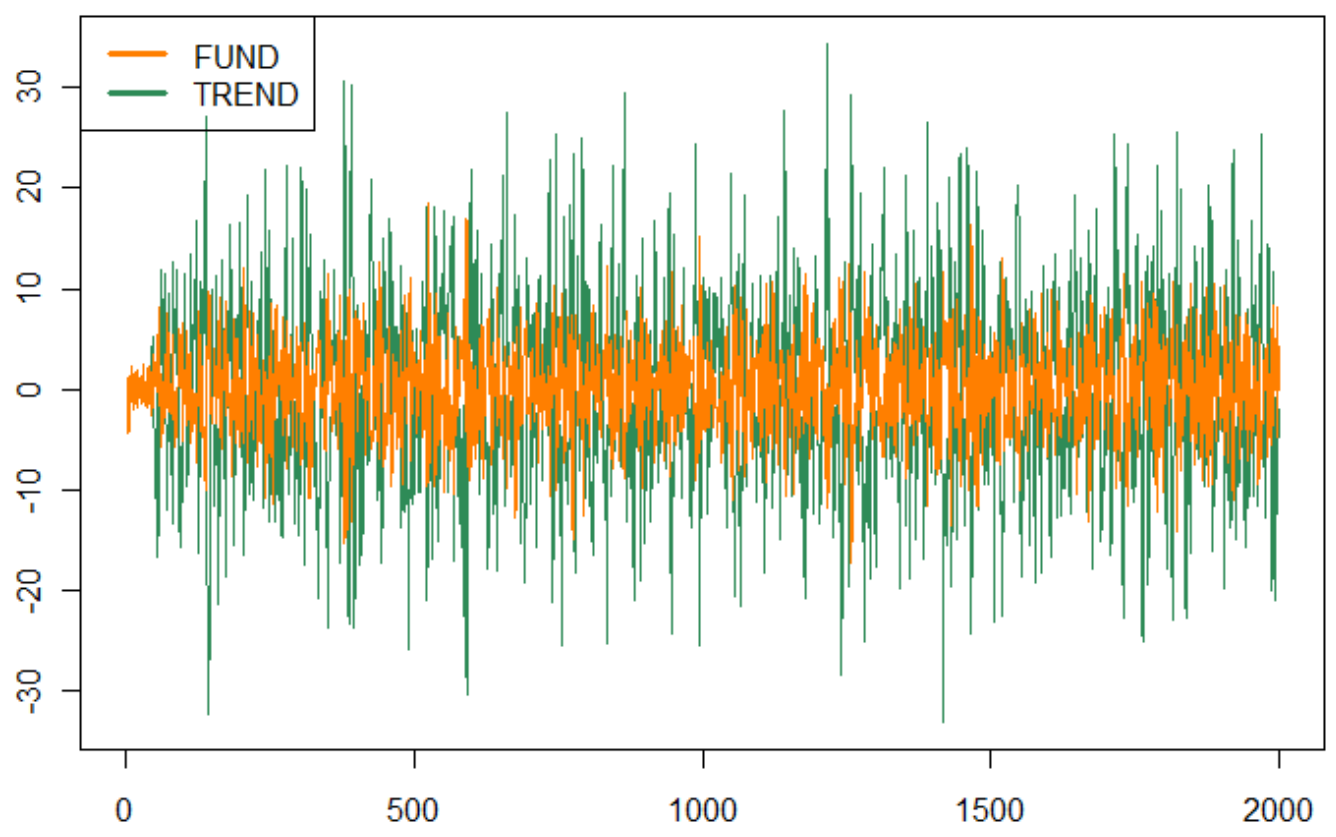

Figure 11 - Average orders from fundamentalist and technical investors for 200 runs

Investor performance. Both the fundamentalist and the technical group are able to make profits (although not all of the agents make profits, the average performance is positive). This was precisely one of the goals when designing our model: it does not make sense from an empirical point of view to use strategies that are not profitable, so we have not used exactly the FJ model, but we have modified the technical strategy so that it is more sophisticated and does not consistently lose money.

Because of their greater positions, technical investors have a bigger weight in price dynamics. Being able to drive trends helps them make money, because entering long (short) positions when the price starts to rise (decrease) is profitable, and moreover their own orders strengthen the price trend. However, fundamentalist investors are also able to take advantage of these price dynamics, because when the difference between price and fundamental value increases their positions become also bigger, and they can earn more money when the price finally converges to the value. 


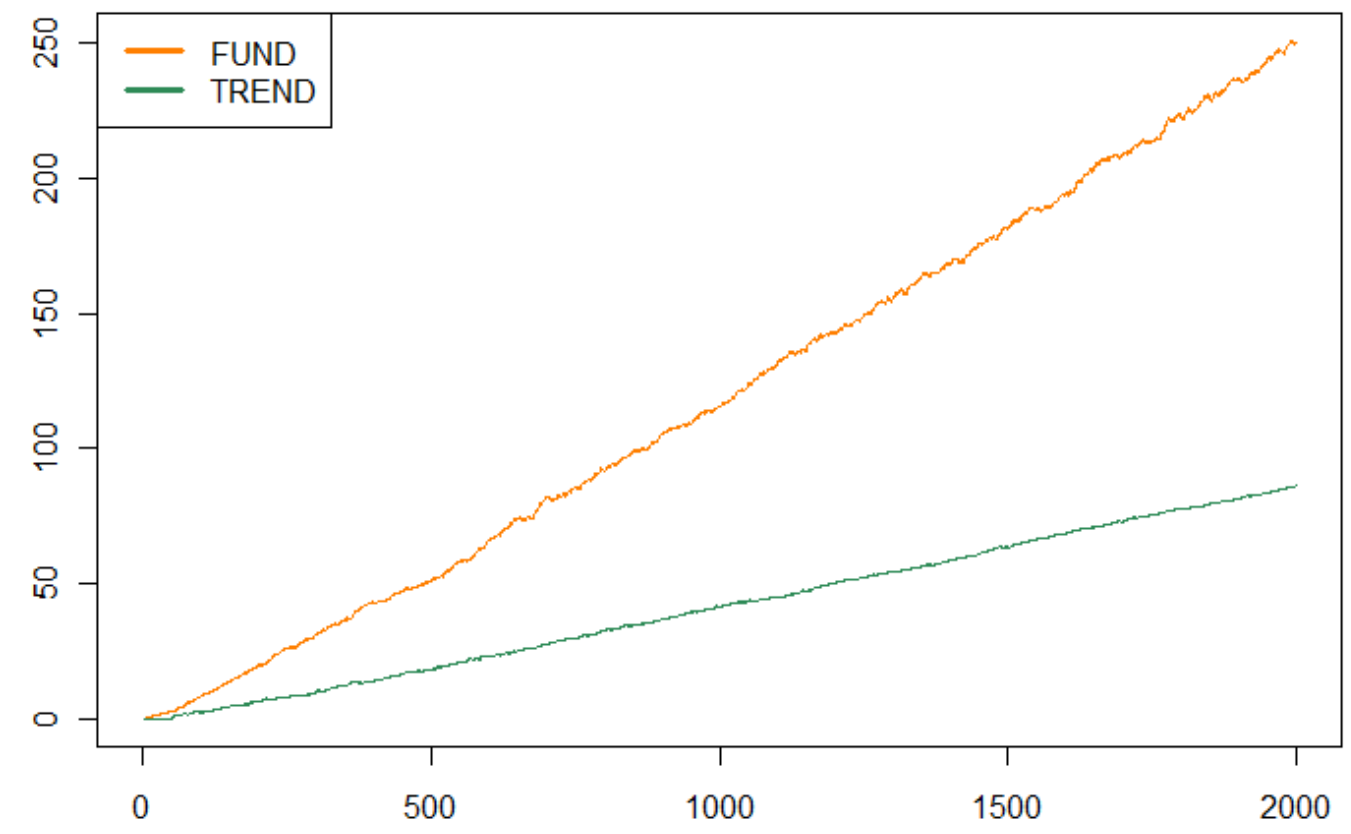

Figure 12 - Average profits ${ }^{4}$ of fundamentalist and technical investors over 200 runs

\subsection{Sensitivity analysis}

To study the effect of parameters on model results, we have performed a sensitivity analysis using the one-factor-at-a-time methodology (ten Broeke, van Voorn, \& Ligtenberg, 2016), varying one parameter at a time to observe its impact on results. This has allowed us to identify the parameters with a most important impact on model dynamics and which will require an specially accurate calibration.

To give an idea of the sensitivity of results, we show below the behaviour of a subset of model outputs under three different parameter values. The selected outputs provide information on several aspects: time evolution of price vs. fundamental value, as an indicator of the overall market dynamics; profits accumulated by fundamentalist and technical traders, as an indicator of agent performance - this indicator is specially relevant given that a new technical strategy has been implemented with the aim of making it competitive; the autocorrelation function of returns and volatility, to gain insight on when the model is able to replicate the lack of return autocorrelation and the clustering of volatility - we have chosen these particular stylised facts with an eye on the posterior phase of output validation because they turn to be the most sensitive ones; and the boxplot of return excess kurtosis and volatility (calculated as the standard deviation of log-returns, without annualising the resulting value), as an indicator of market stability and return non-normality.

We provide next a summary of the results of the sensitivity analysis for each parameter:

\footnotetext{
${ }^{4}$ Benefits obtained by agent $i$ are calculated as the profits accumulated since the start of the simulation due to changes in price:
}

$$
\operatorname{Ben}_{t}^{i}=\operatorname{Ben}_{t-1}^{i}+\operatorname{pos}_{t-1}^{i} \cdot\left(P_{t}-P_{t-1}\right)
$$


- Parameters associated to price formation

- Liquidity is coupled to the number of agents (the more agents in the market, the higher the liquidity), and when these parameters move in tandem no significant change is observed in market results.

- Standard deviation of noise term: When $\sigma_{P}$ increases, the price gets more volatile as the random term added to the price formation process (see equation ( 1 )) takes higher values. Figure 13 shows that this has a special impact on FUNDs' performance: as the price takes a wider range of values (Figure 13 (a)), its difference with respect to the fundamental value rises, and in consequence the fundamentalist positions also increase. The weight of fundamentalist agents in price formation gets higher, which results advantageous to this type of traders and translates in better profits (Figure 13 (b)).

(a) Price vs. Fundamental value

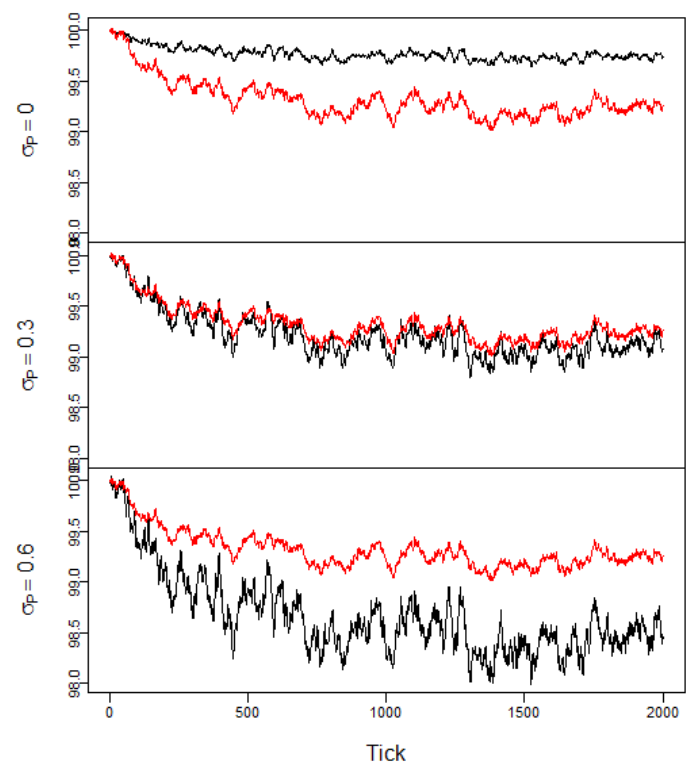

(c) ACF of log-returns

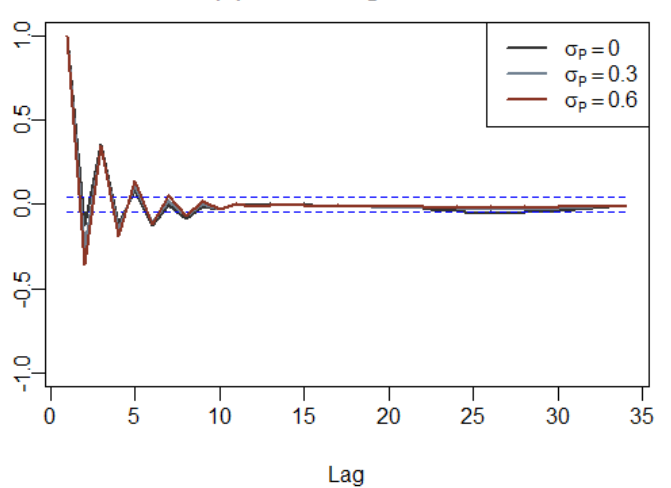

(b) Accumulated wealth

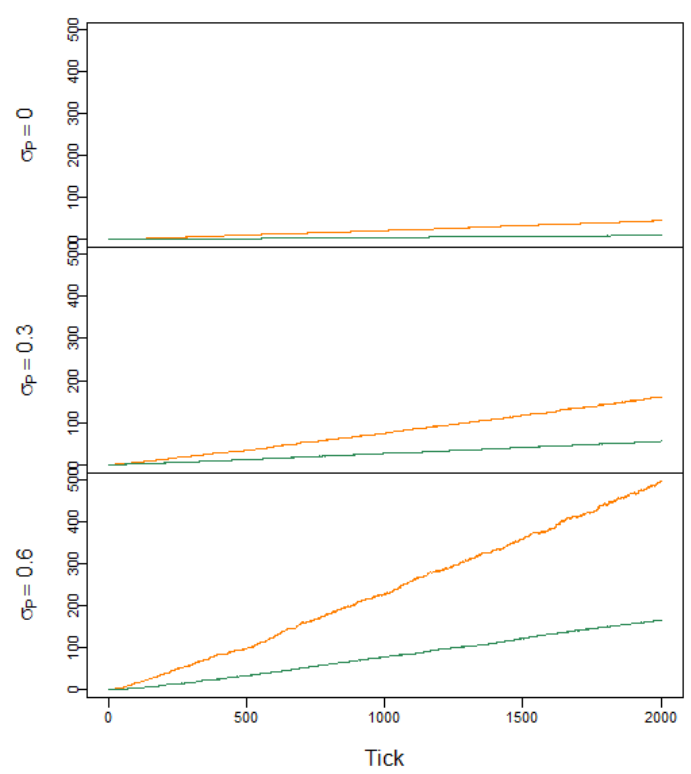

(d) ACF of squared log-returns

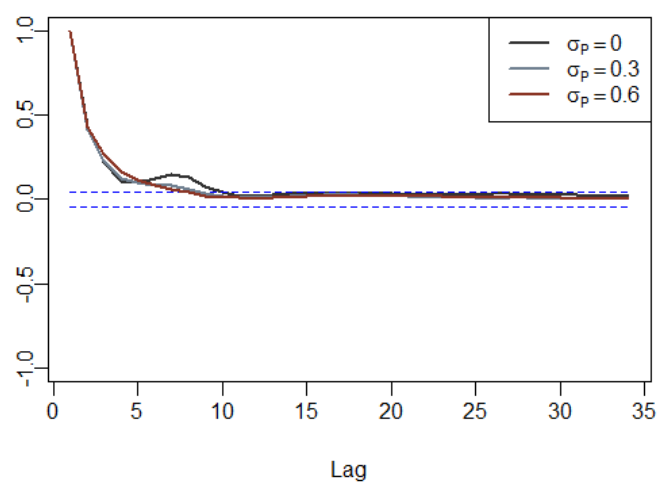


(e) Return excess kurtosis

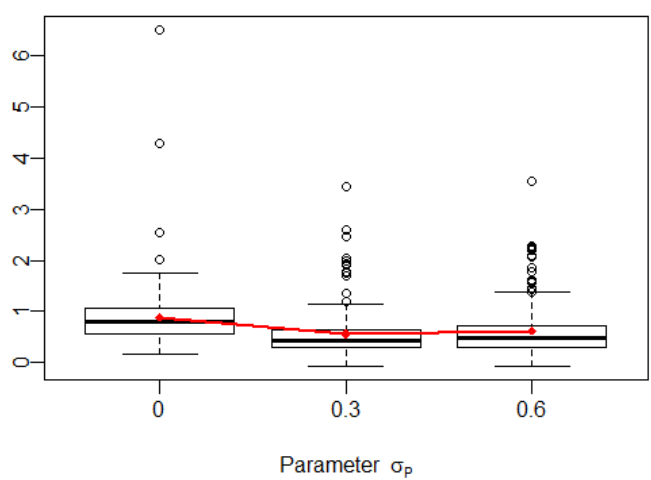

(f) Return volatility

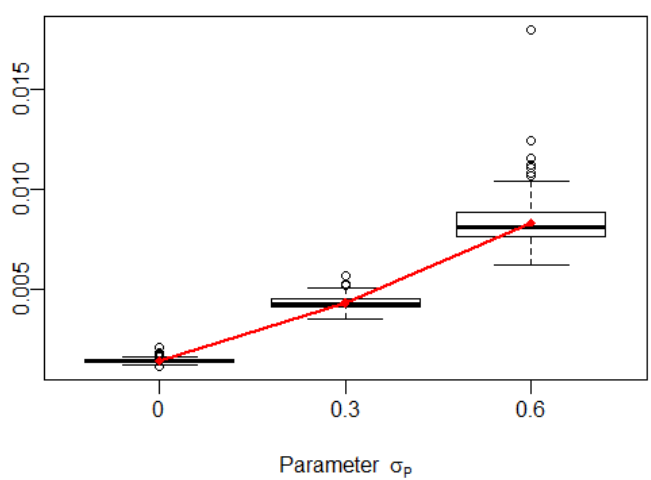

Figure 13 - Sensitivity of model outputs to parameter $\sigma_{P}$. (a) Average of price (in black) and fundamental value (in red). (b) Average profits of fundamentalist (in orange) and technical (in green) traders. (c) Average autocorrelation of returns. (d) Average autocorrelation of squared returns. (e) Boxplot of return kurtosis. (f) Boxplot of return standard deviation. All averages are calculated over 200 runs.

- Parameters associated to fundamental value formation

- Standard deviation: The model outputs are not much sensitive to the standard deviation of the process of fundamental value formation, the parameter $\sigma_{V}$. As shown in Figure 14, an increase in $\sigma_{V}$ has an obvious effect on the volatility of the fundamental price process (in red in Figure 14 (a)). This leads fundamentalist traders to move a higher volume as the difference between price and fundamental value increases, and this has a positive effect in their profits. The higher orders sent by fundamentalist agents rise the range of price movements (volatility increases in Figure 14 (f)) but has a small effect in their pattern, so the autocorrelation of returns and volatility barely change (Figure 14 (c), (d)).

(a) Price vs. Fundamental value

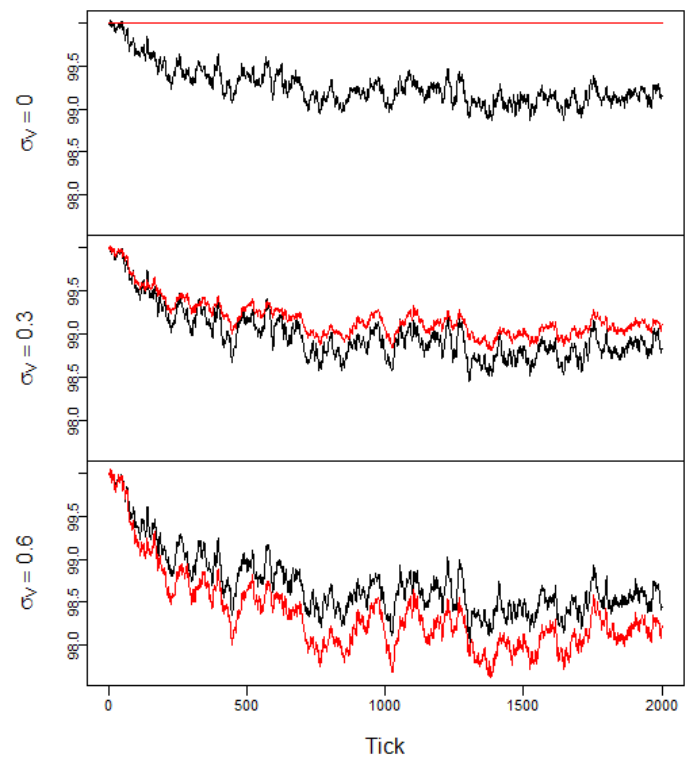

(b) Accumulated wealth

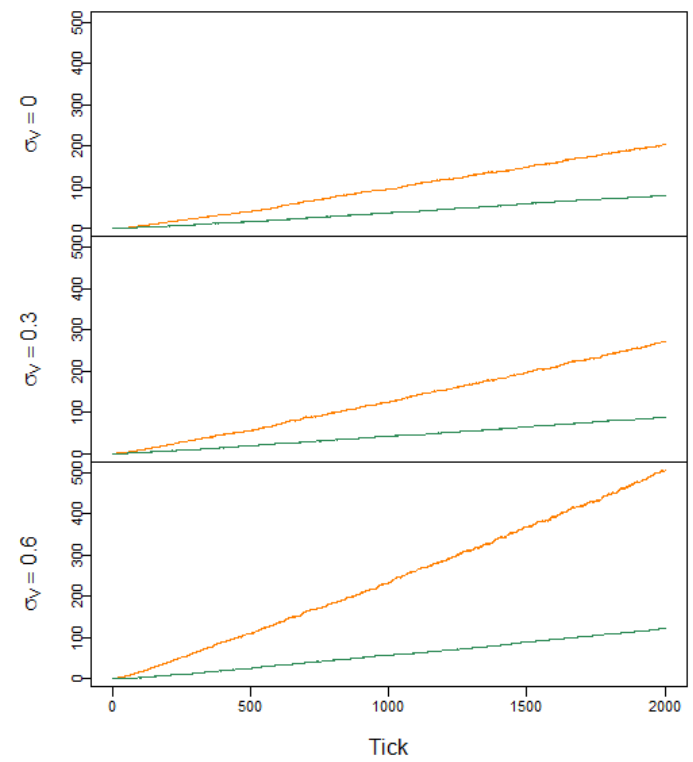


(c) ACF of log-returns

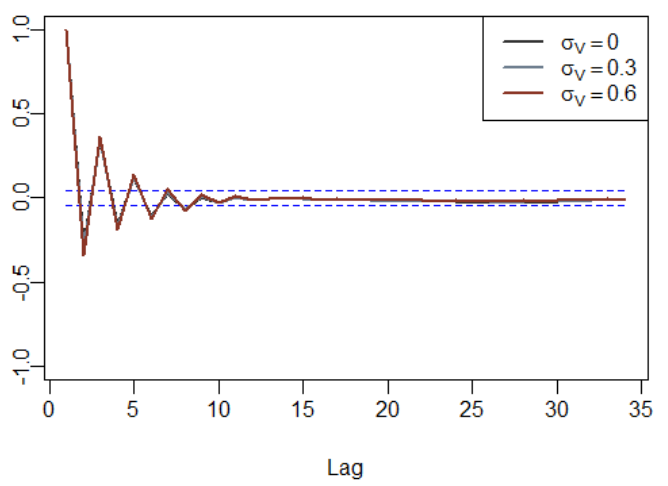

(e) Return excess kurtosis

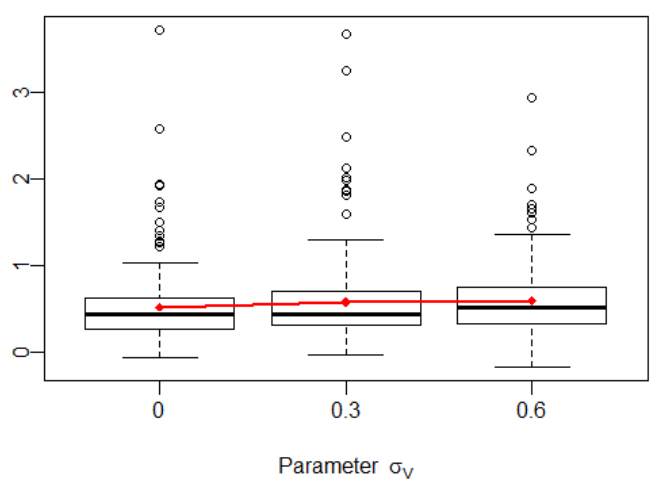

(d) ACF of squared log-returns

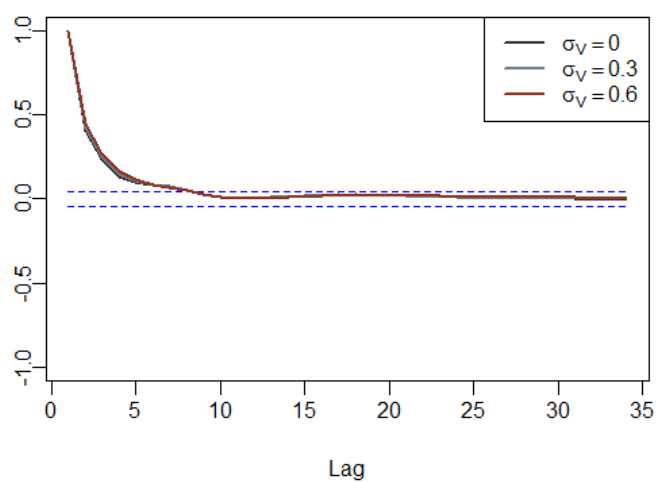

(f) Return volatility

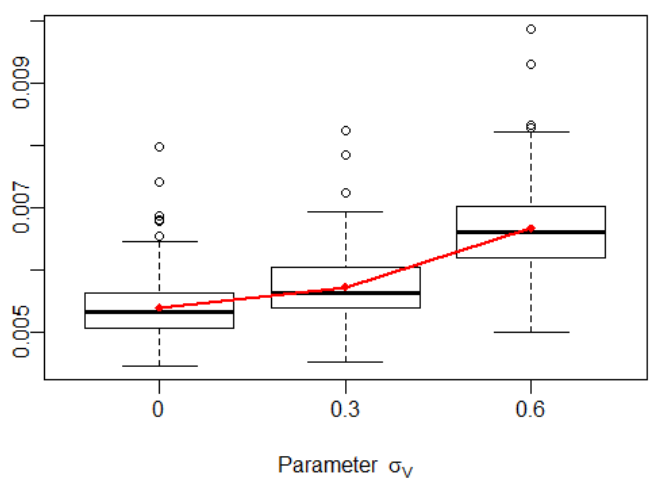

Figure 14 - Sensitivity of model outputs to parameter $\sigma_{V}$. (a) Average of price (in black) and fundamental value (in red). (b) Average profits of fundamentalist (in orange) and technical (in green) traders. (c) Average autocorrelation of returns. (d) Average autocorrelation of squared returns. (e) Boxplot of return kurtosis. (f) Boxplot of return standard deviation. All averages are calculated over 200 runs.

- Parameters associated to the fundamentalist strategy

- Entry threshold: Simulation results are not much sensitive to the parameters associated to the FUND strategy (entry threshold, exit threshold and the offset that accounts for the variability in the agent perception of the fundamental value). Among these three parameters, the entry threshold is the one with a most significant impact on outputs: When the entry threshold increases, it is more difficult for fundamentalist traders to enter a position, as they need to wait for a bigger divergence between the price and the perceived fundamental value. This reduces the volume of fundamentalist orders and their profits (Figure 15 (b)), but the effect in other model outputs is not remarkable. 
(a) Price vs. Fundamental value

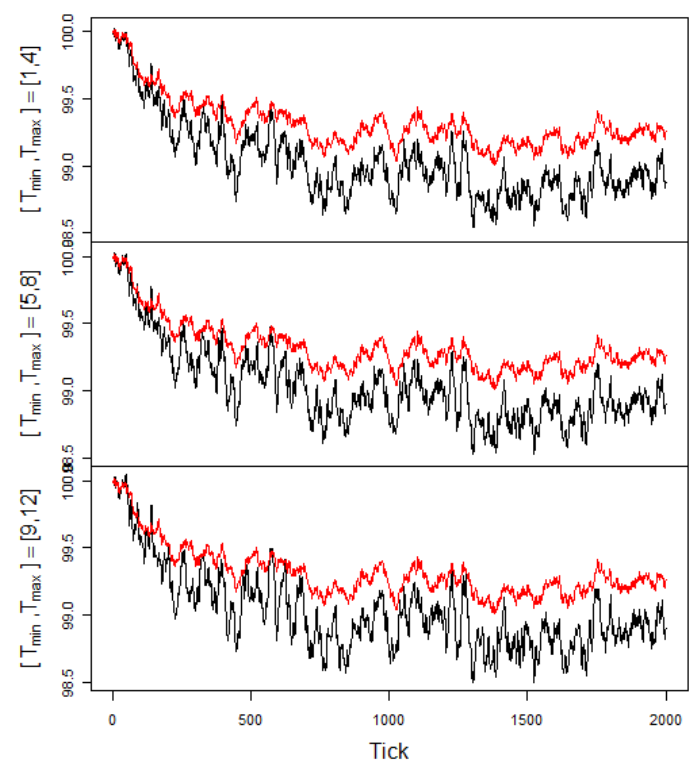

(c) ACF of log-returns

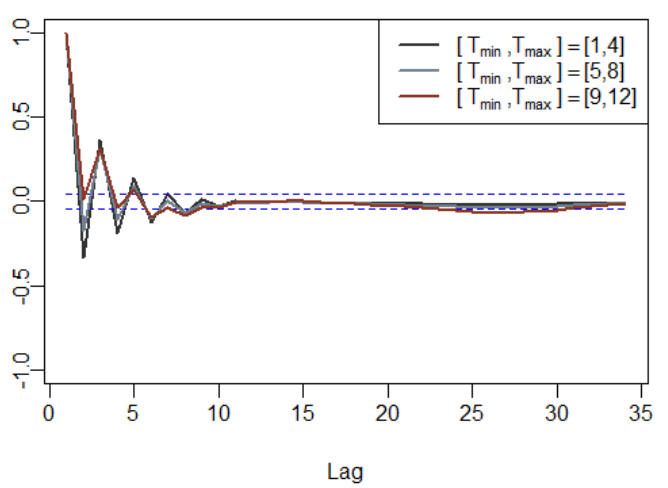

(e) Return excess kurtosis

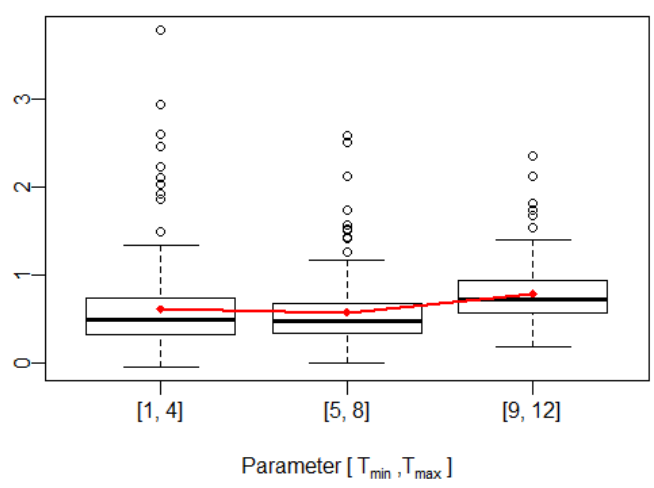

(b) Accumulated wealth

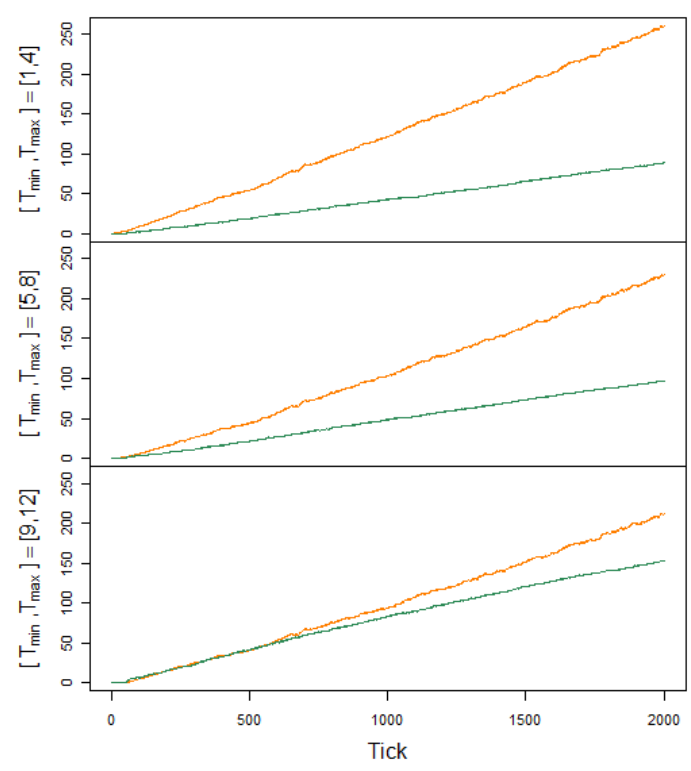

(d) ACF of squared log-returns

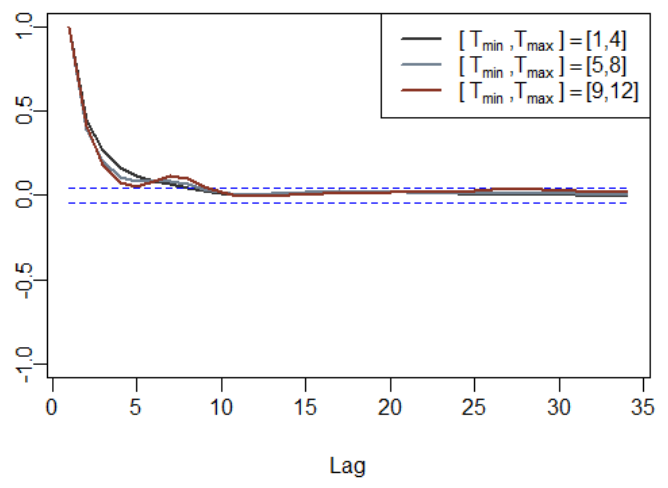

(f) Return volatility

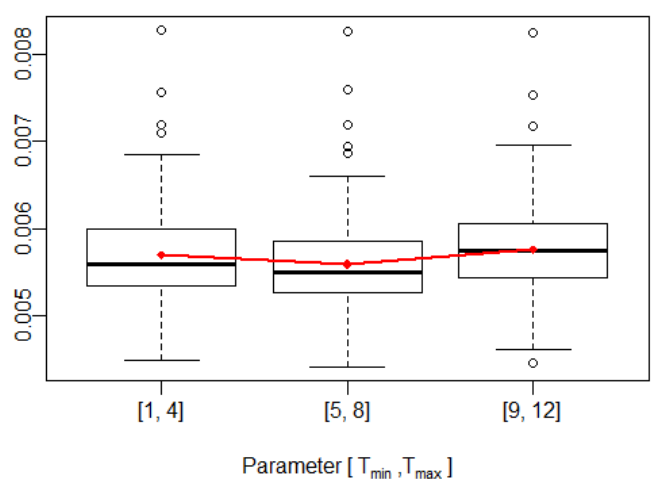

Figure 15 - Sensitivity of model outputs to FUND entry threshold $\left[T_{\min }, T_{\max }\right]$. (a) Average of price (in black) and fundamental value (in red). (b) Average profits of fundamentalist (in orange) and technical (in green) traders. (c) Average autocorrelation of returns. (d) Average autocorrelation of squared returns. (e) Boxplot of return kurtosis. (f) Boxplot of return standard deviation. All averages are calculated over 200 runs.

- Exit threshold: When the exit threshold increases, it is easier for fundamentalist traders to close a position. However, their volume does not change too much, because with a low exit threshold fundamentalist agents do not close their 
positions that often, but reduce them gradually until the difference between price and fundamental value is small enough and so in the end the volume is similar in both cases. For this reason, the model results show a low sensitivity to this parameter (Figure 16).

(a) Price vs. Fundamental value

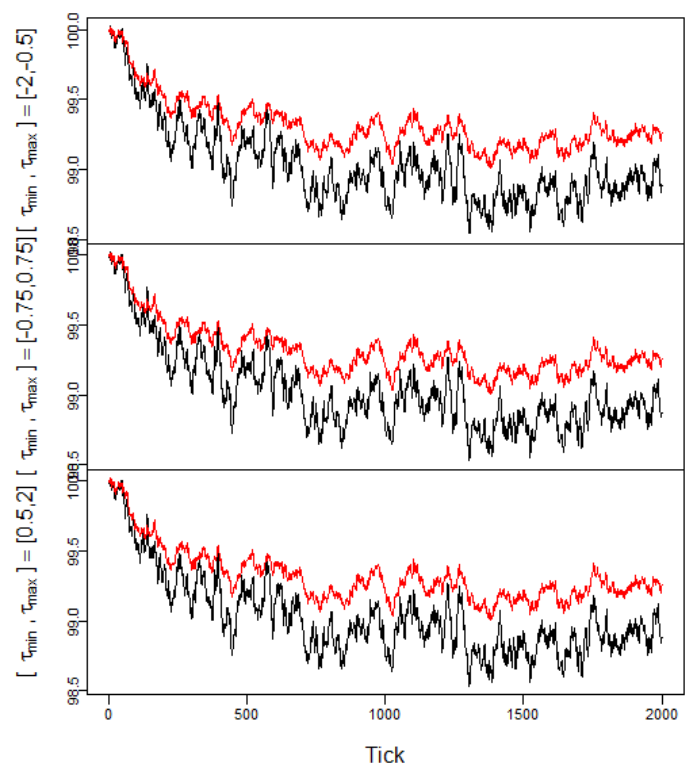

(c) ACF of log-returns

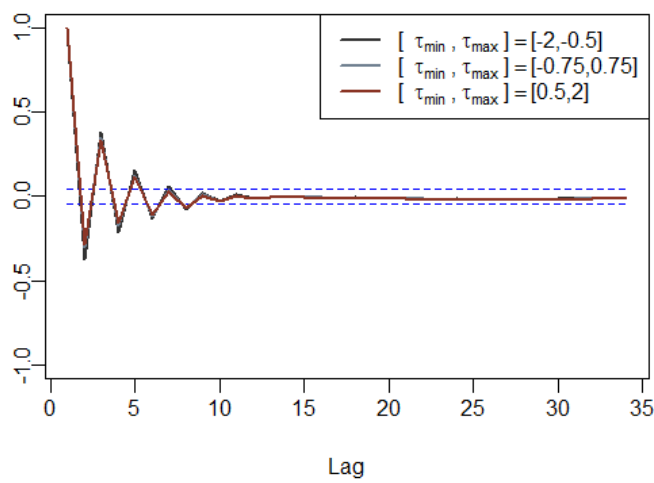

(e) Return excess kurtosis

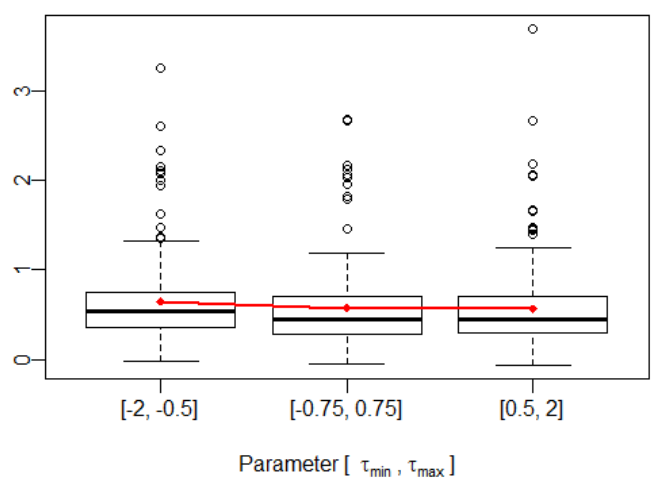

(b) Accumulated wealth

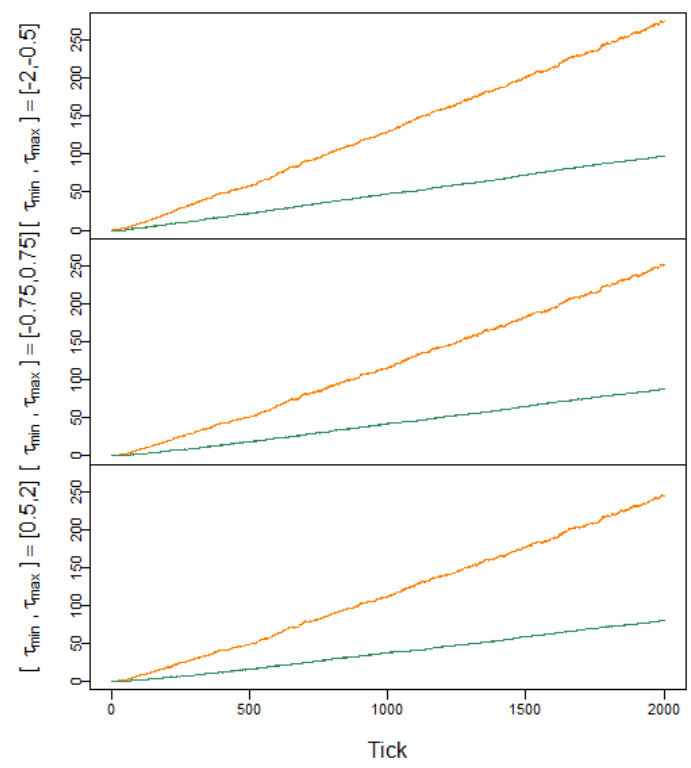

(d) ACF of squared log-returns

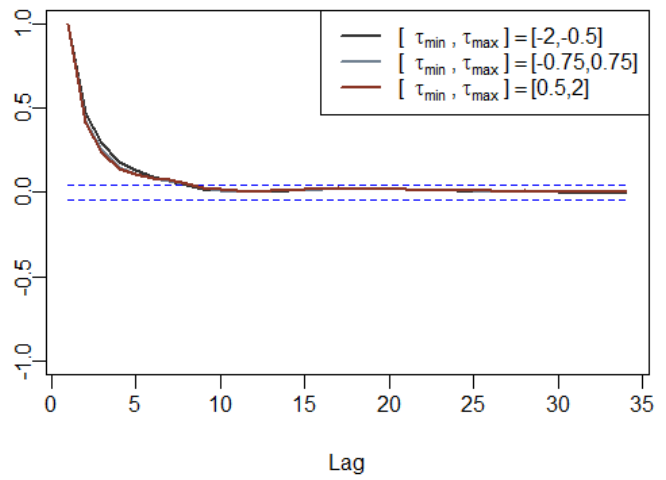

(f) Return volatility

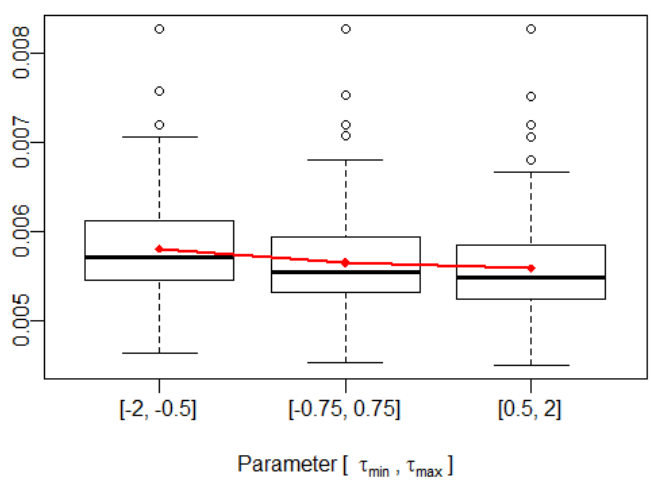

Figure 16 - Sensitivity of model outputs to FUND exit threshold $\left[\tau_{\min }, \tau_{\max }\right]$. (a) Average of price (in black) and fundamental value (in red). (b) Average profits of fundamentalist (in orange) and technical (in green) traders. (c) Average autocorrelation of returns. (d) Average autocorrelation of squared returns. (e) Boxplot of return kurtosis. (f) Boxplot of return standard deviation. All averages are calculated over 200 
runs.

- Value offset: When the value offset rises, it gets easier for the fundamentalist traders to open a position, because the difference between the price and their perceived fundamental value is higher and so it is more likely to surpass the entry threshold. For this reason, the volume moved by fundamentalist agents tends to increase, but their net effect in price dynamics is not significant because of the symmetry in the range of values of the offset: as fundamentalist traders have the same probability to have a positive or a negative offset, they are approximately equally likely to enter long or short positions and so the aggregated orders do not show a big variation when the offset goes up. As a result, the model ouputs show a small sensitivity to this parameter (Figure 17).

(a) Price vs. Fundamental value

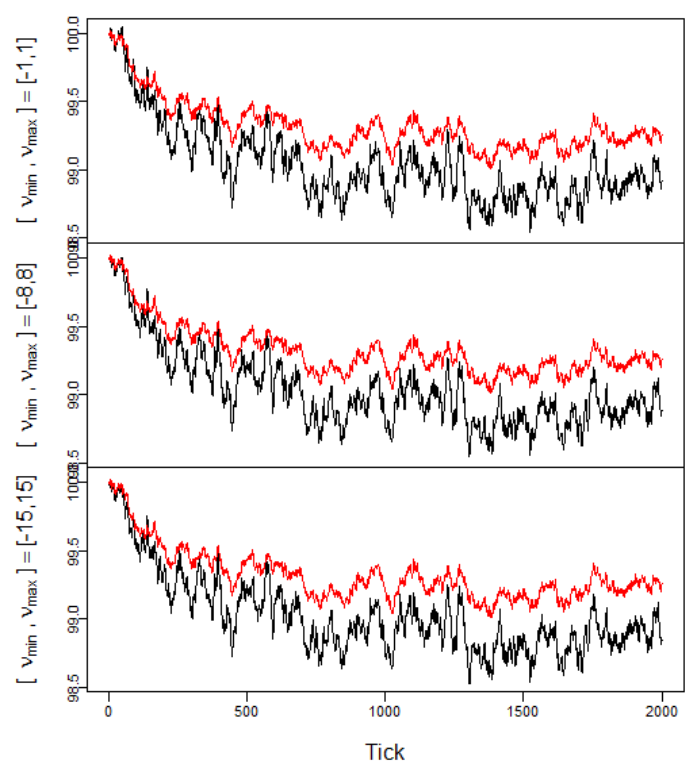

(c) ACF of log-returns

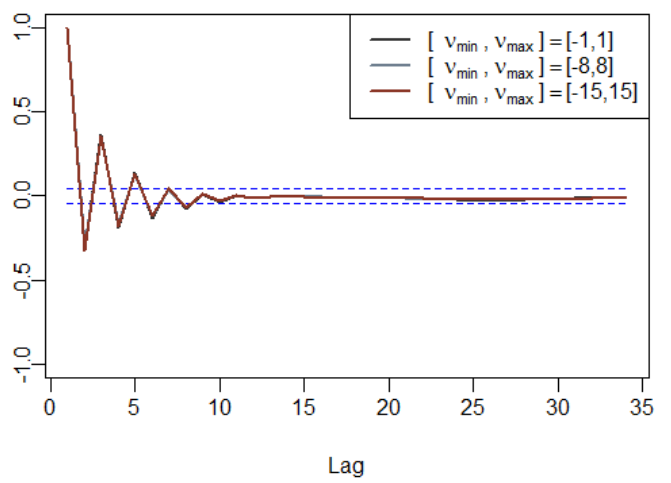

(b) Accumulated wealth

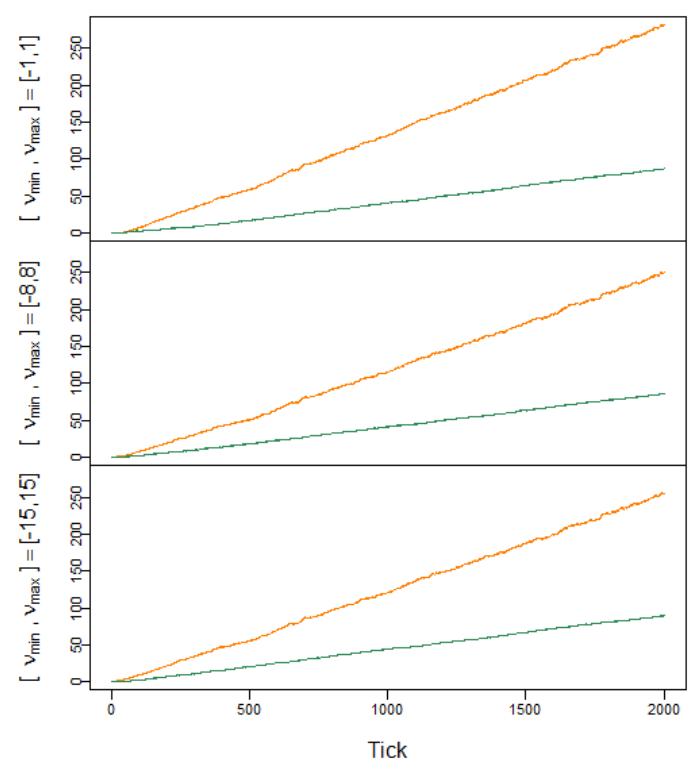

(d) ACF of squared log-returns

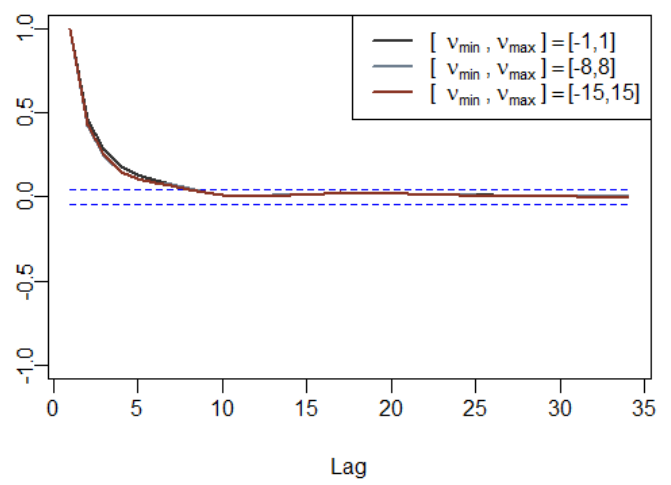


(e) Return excess kurtosis

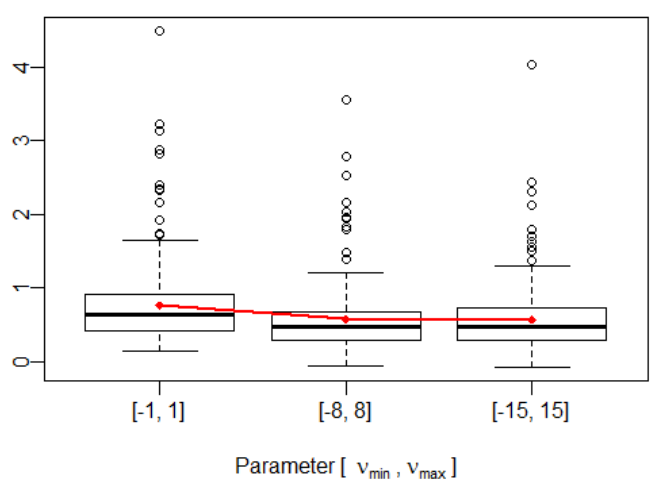

(f) Return volatility

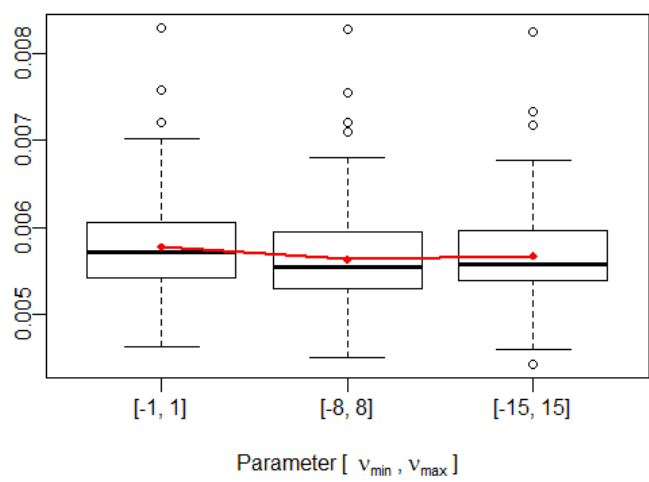

Figure 17 - Sensitivity of model outputs to FUND offset $\left[v_{\min }, v_{\max }\right]$. (a) Average of price (in black) and fundamental value (in red). (b) Average profits of fundamentalist (in orange) and technical (in green) traders. (c) Average autocorrelation of returns. (d) Average autocorrelation of squared returns. (e) Boxplot of return kurtosis. (f) Boxplot of return standard deviation. All averages are calculated over 200 runs.

- Parameters associated to the technical strategy

- Window of short-term moving average: When the value of the short-term moving average is low - specially, when it is close to $1,-$ then the price shows a more volatile behaviour (Figure 18 (a)): when the short-term window is small, the technical entry indicator (given by the difference in slopes of the short- and the long-term moving averages of prices) becomes quite sensitive, as any movement up or down in the price can induce a change in the slope of the short-term moving average, and the joint action of technical traders can cause a marked movement in the price. This notable effect in prices results in higher profits for technical traders (Figure 18 (b)), but fundamentalists also take advantage of the situation because the higher divergence of price with respect to fundamental value results in higher fundamentalist positions which lead to more substantial profits when the price reverts. When the short-term window increases, it has a smoothing effect that prevents the peaks in the price series (Figure $18(\mathrm{c}),(\mathrm{d}))$ and so the kurtosis and volatility of returns go down (Figure $18(\mathrm{e}),(\mathrm{f}))$. 
(a) Price vs. Fundamental value

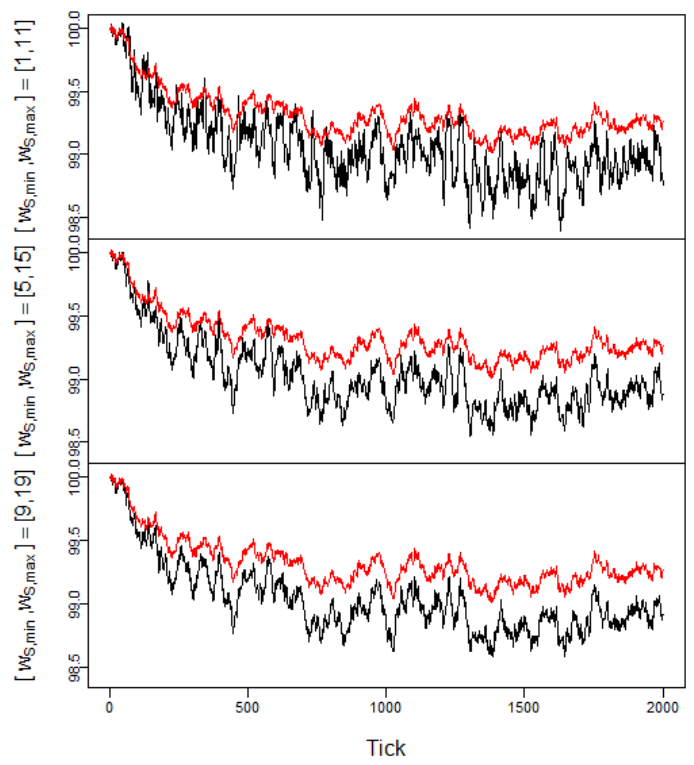

(c) ACF of log-returns

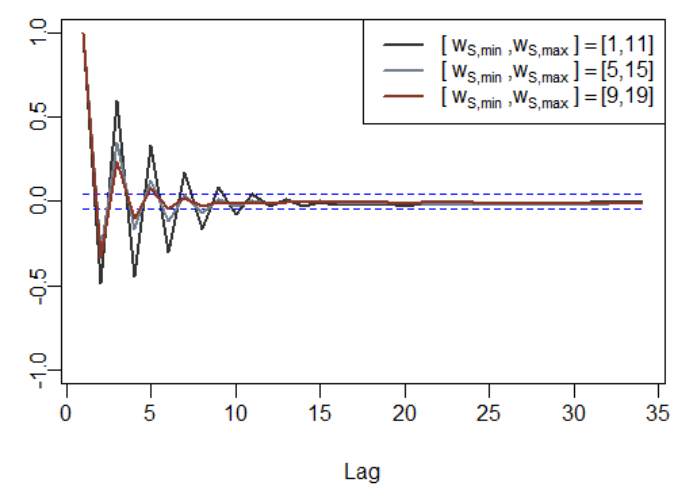

(e) Return excess kurtosis

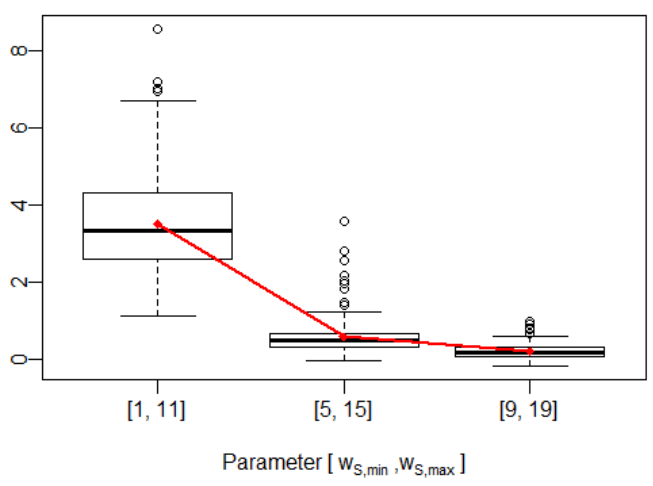

(b) Accumulated wealth

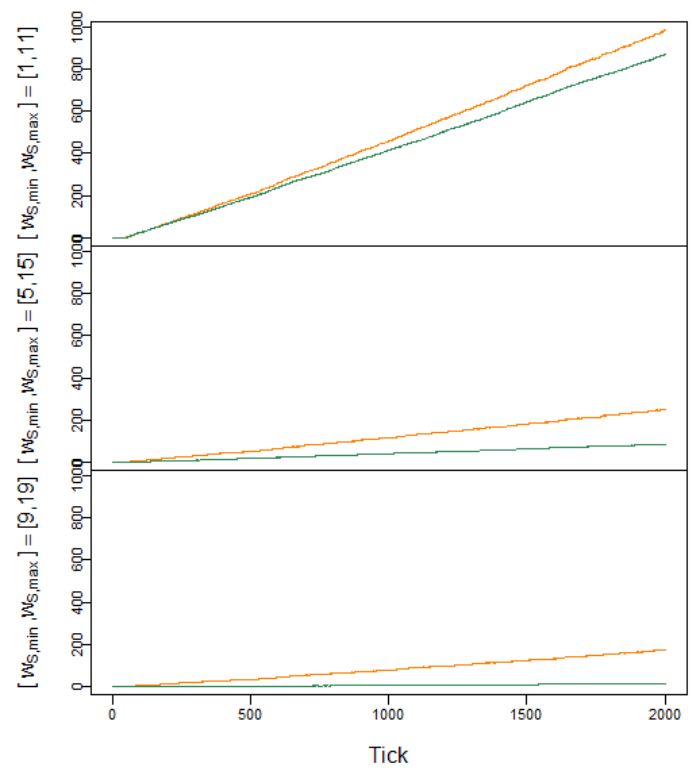

(d) ACF of squared log-returns

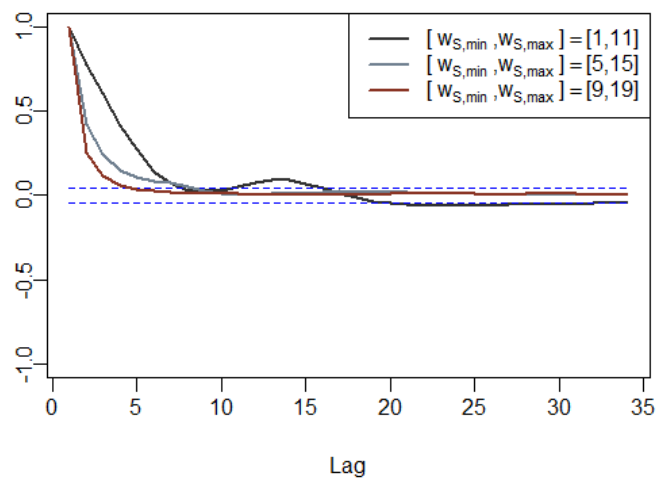

(f) Return volatility

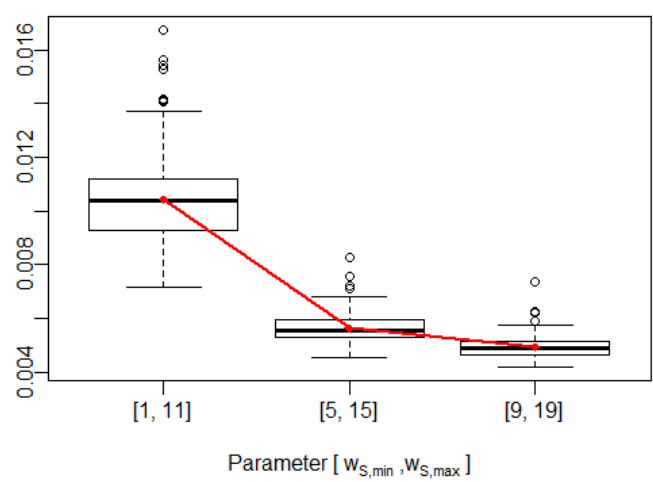

Figure 18 - Sensitivity of model outputs to TREND short-term MA window $\left[w_{S, \operatorname{tin}}^{t r}, w_{S, \max }^{t r}\right]$. (a) Average of price (in black) and fundamental value (in red). (b) Average profits of fundamentalist (in orange) and technical (in green) traders. (c) Average autocorrelation of returns. (d) Average autocorrelation of squared returns. (e) Boxplot of return kurtosis. (f) Boxplot of return standard deviation. All averages are calculated over 200 runs.

- Window of long-term moving average: A variation in the window of the longterm moving average has a less noticeable effect in the results than the short- 
term window, as the smoothing effect obtained when increasing the window is less significant for larger values of this window (Figure 19).

(a) Price vs. Fundamental value

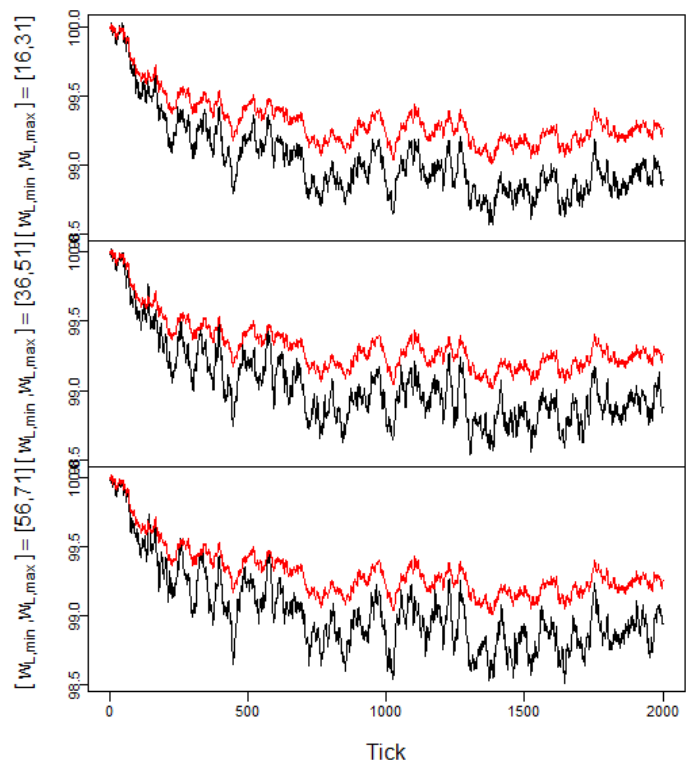

(c) ACF of log-returns

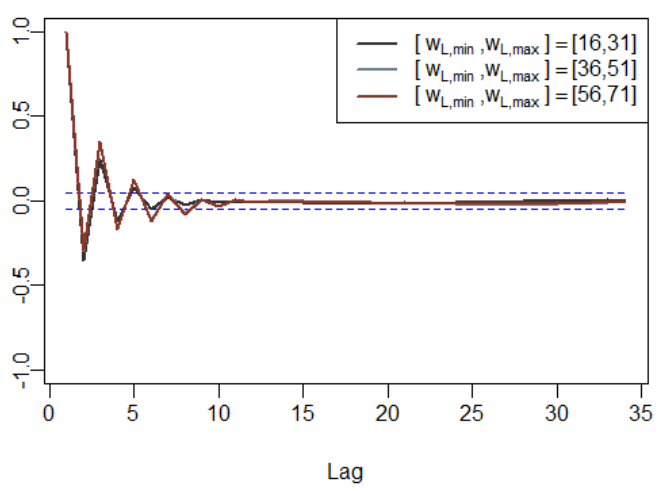

(e) Return excess kurtosis

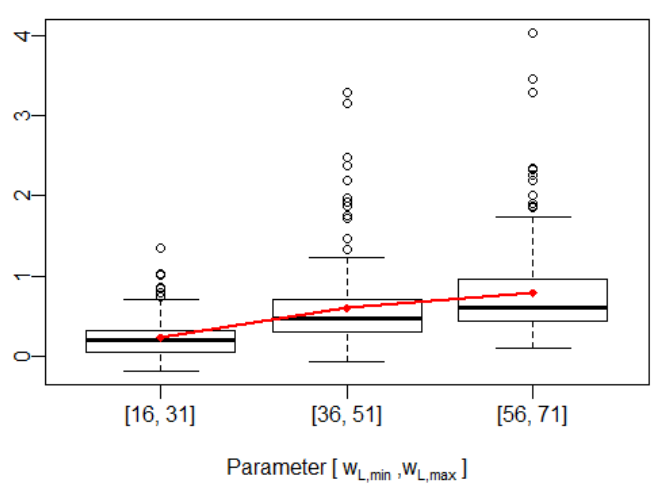

(b) Accumulated wealth

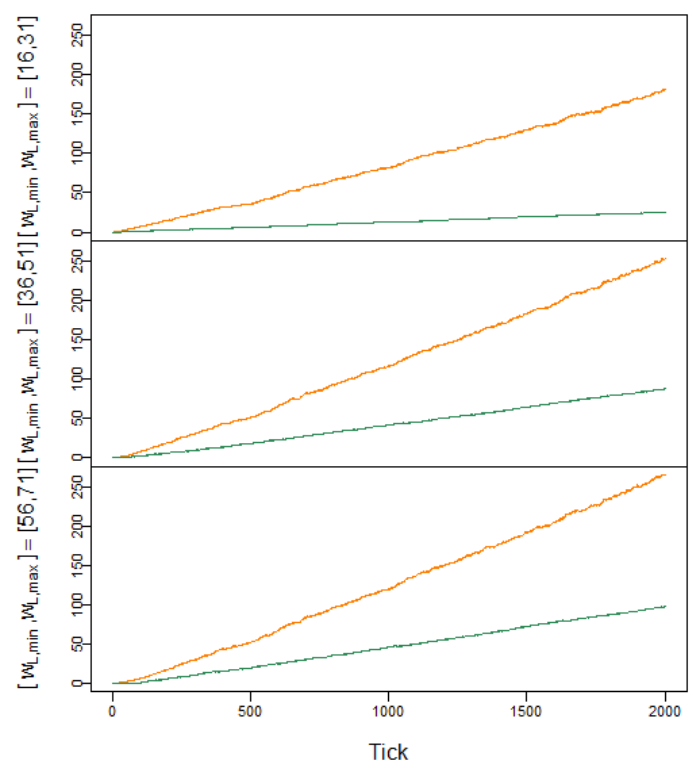

(d) ACF of squared log-returns

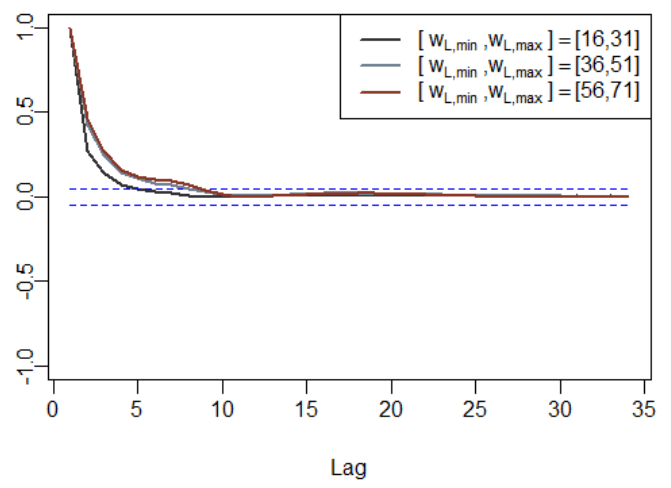

(f) Return volatility

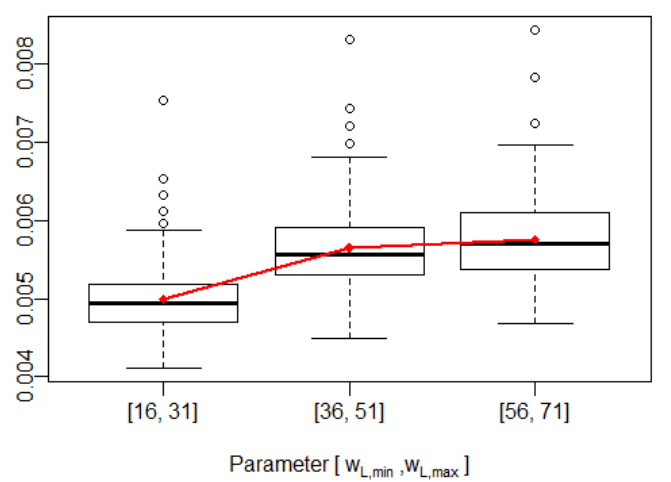

Figure 19 - Sensitivity of model outputs to TREND long-term MA window $\left[w_{L, \min }^{t r}, w_{L, \max }^{t r}\right]$. (a) Average of price (in black) and fundamental value (in red). (b) Average profits of fundamentalist (in orange) and technical (in green) traders. (c) Average autocorrelation of returns. (d) Average autocorrelation of squared returns. (e) Boxplot of return kurtosis. (f) Boxplot of return standard deviation. All averages are calculated over 200 runs. 
- Window of exit channel: When the window of the exit channel increases, technical traders are forced to keep their positions for longer. When they finally are 'allowed' to close a position after keeping it open during a long period of time, it is likely that the price trend which left them to enter their current positions has reversed, and so technical traders liquidate their portfolios. If they do so more or less simultaneously, they move the price and make higher profits (Figure 20 (b)), but increase the kurtosis and volatility of returns (Figure 20 (e), (f)). The price movements concentrated in short intervals of time also increase the autocorrelation of returns (Figure 20 (c)) and the clustering of volatility (Figure 20 (d)).

(a) Price vs. Fundamental value

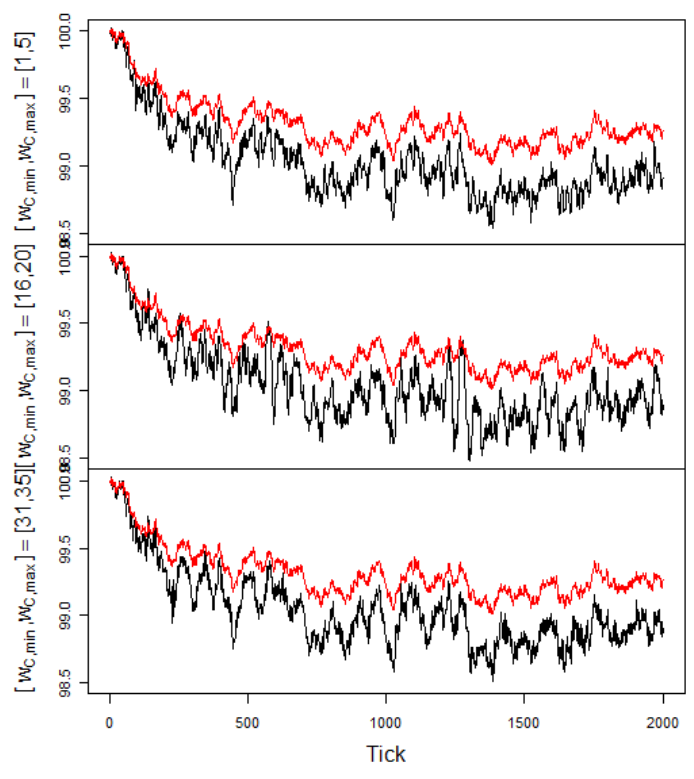

(c) ACF of log-returns

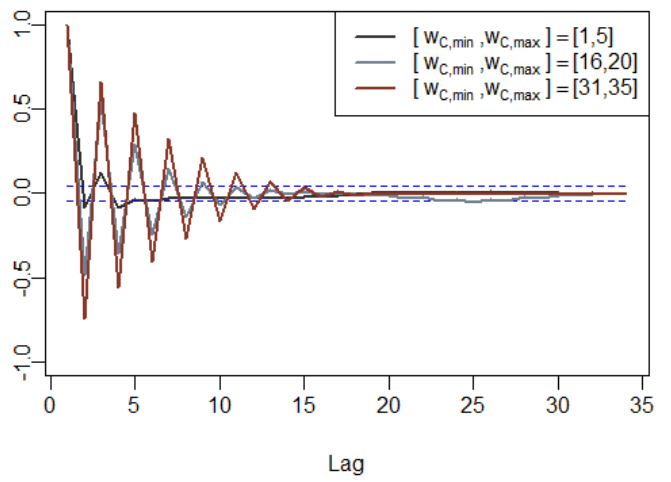

(b) Accumulated wealth

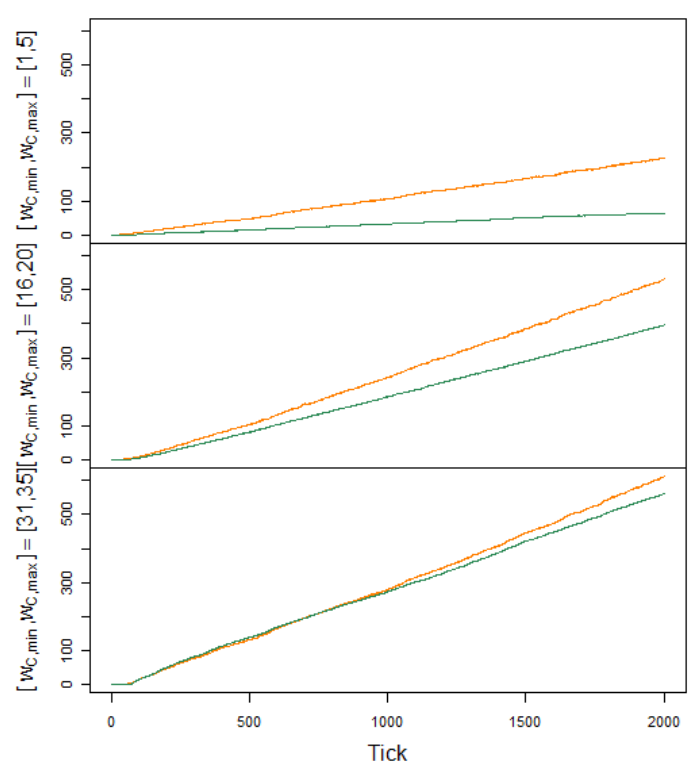

(d) ACF of squared log-returns

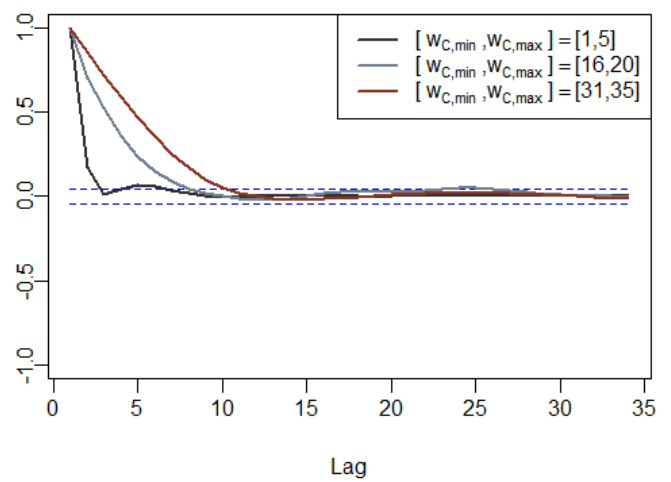


(e) Return excess kurtosis

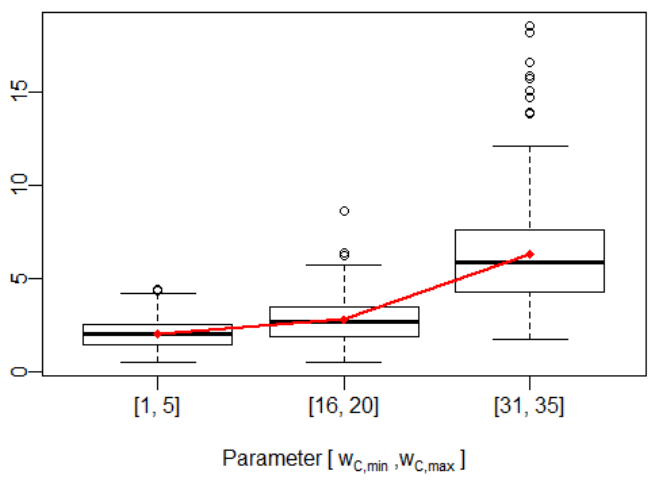

(f) Return volatility

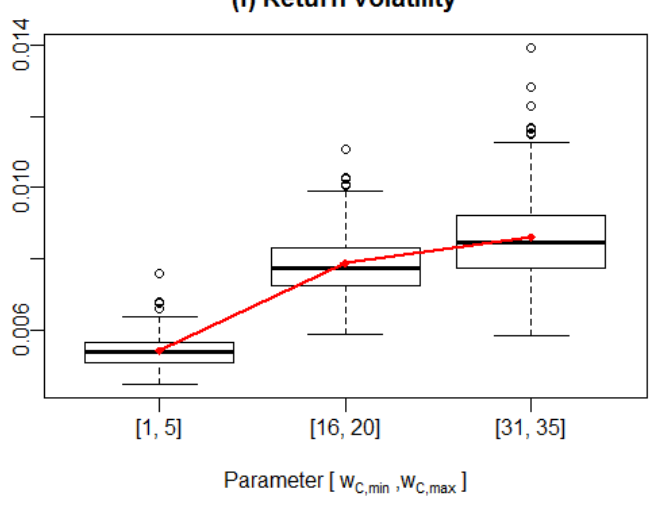

Figure 20 - Sensitivity of model outputs to TREND exit channel window $\left[w_{C, \min }^{t r}, w_{C, \max }^{t r}\right]$. (a) Average of price (in black) and fundamental value (in red). (b) Average profits of fundamentalist (in orange) and technical (in green) traders. (c) Average autocorrelation of returns. (d) Average autocorrelation of squared returns. (e) Boxplot of return kurtosis. (f) Boxplot of return standard deviation. All averages are calculated over 200 runs.

- Proportion of fundamentalist/technical traders: We could study the effect of the total number of agents, but as said above it is insignificant as long as it increases or decreases at the same time than the liquidity parameter. A more interesting situation is obtained when the proportion of fundamentalist to technical agents is altered. Figure 21 shows that when the market is dominated by technical traders (that is, when the proportion of fundamentalist agents is $25 \%$ ) the price exhibits high jumps ${ }^{5}$ : when there is an incipient trend in price series, the technical traders propel it until the distance from the fundamental value is high enough for the minority of fundamentalist agents to be able to reverse it. This scenario directly leads to higher return kurtosis and volatility (Figure 21 (e), (f)), and also has an impact on the profits obtained by the agents (Figure 21 (b)): technical traders take advantage of the momentum they induce in prices, whereas when the price reverts fundamentalist traders also profit from the higher positions accumulated due to the marked divergences between price and fundamental value. The effect of a technical dominance is also noticeable in the ACF curves, which show bulges due to the anticorrelation induced by the technical strategy.

When the proportion of fundamentalist agents is equal or higher than the proportion of technical agents, then price dynamics get a more realistic appearance as the action of fundamentalist traders induce a dynamic similar to that of a random walk.

\footnotetext{
5 The average price in Figure 21 (a) seems to oscillate, but this is only due to the averaging. In the price series obtained from individual runs, there are jumps in the price process that look like oscillations in the average price series.
} 
(a) Price vs. Fundamental value

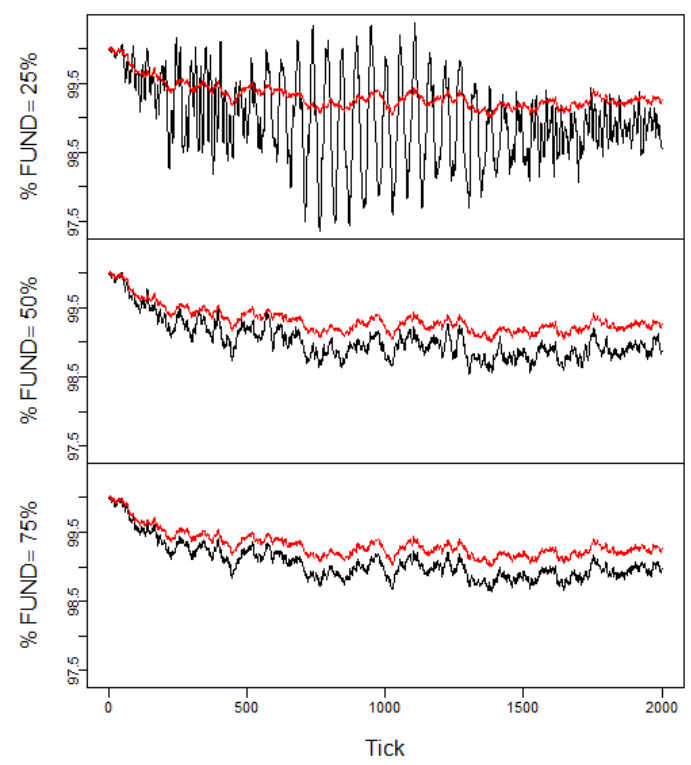

(c) ACF of log-returns

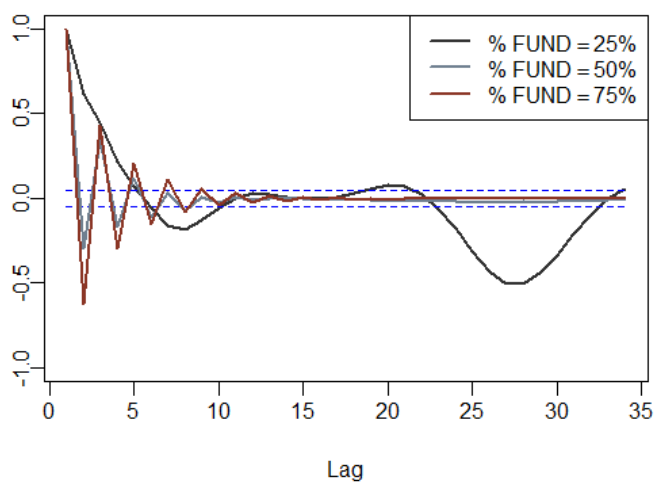

(e) Return excess kurtosis

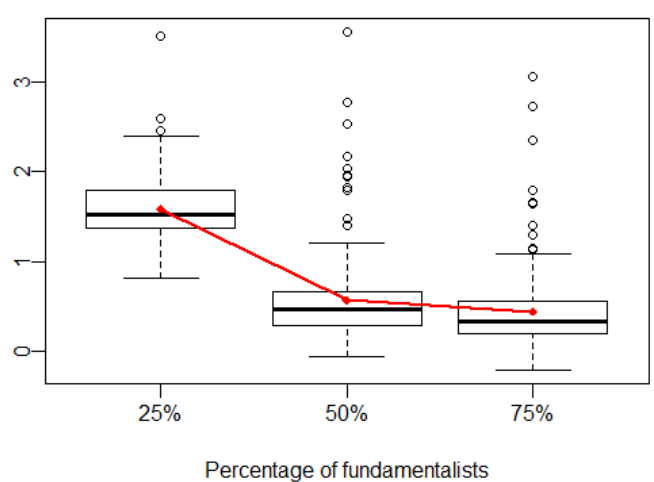

(b) Accumulated wealth

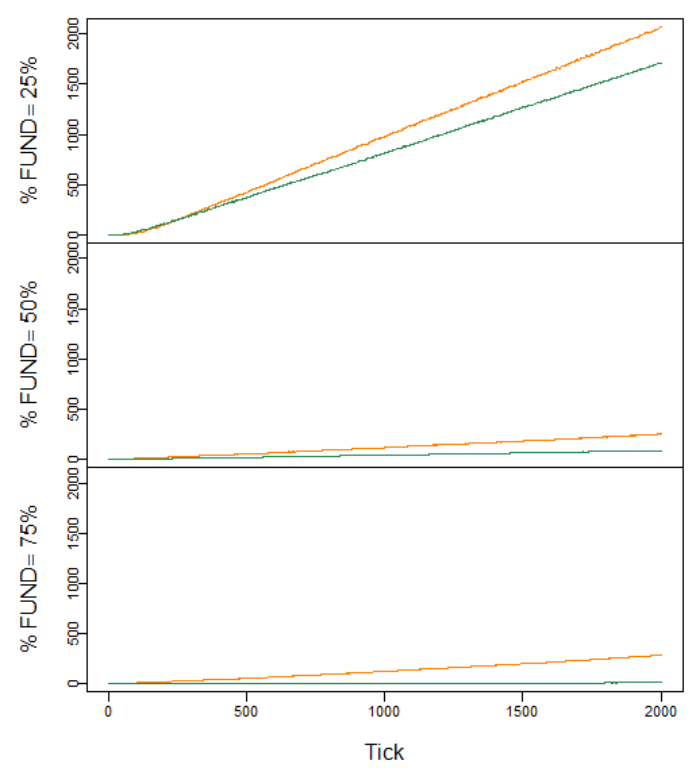

(d) ACF of squared log-returns

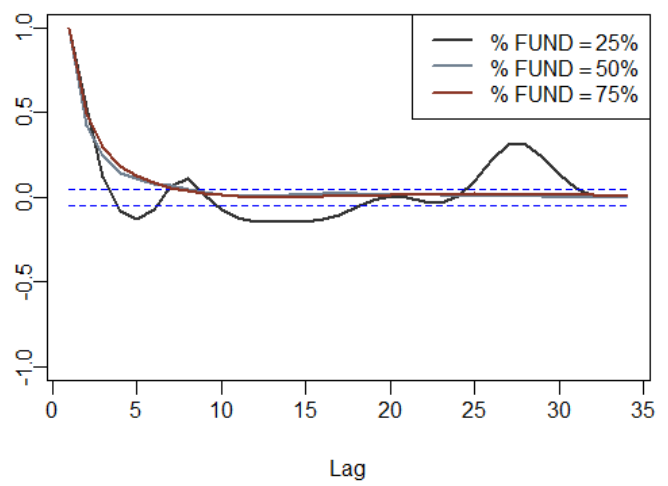

(f) Return volatility

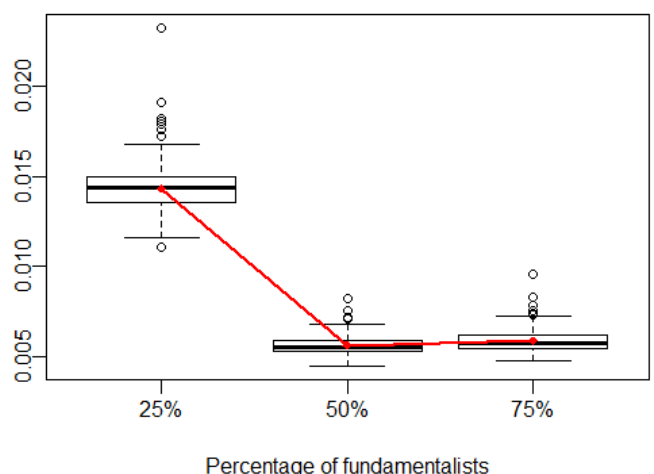

Figure 21 - Sensitivity of model outputs to the percentage of fundamentalist traders. (a) Average of price (in black) and fundamental value (in red). (b) Average profits of fundamentalist (in orange) and technical (in green) traders. (c) Average autocorrelation of returns. (d) Average autocorrelation of squared returns. (e) Boxplot of return kurtosis. (f) Boxplot of return standard deviation. All averages are calculated over 200 runs. 


\subsection{Calibration}

A handful of quantitative methods have been proposed to calibrate agent-based financial models. For example, Fabretti (2013) uses the optimisation method put forward by Gilli and Winker (2003) and a genetic algorithm to calibrate parameters, and Alfarano et al. (2005) propose to use the method of maximum likelihood to estimate the parameters of a model for which a closed-form return distribution can be derived.

In contrast to these technical methods, the approach we have used to calibrate the parameters of our model is far more straightforward and intuitive. As there is a direct correspondence between the behaviour of artificial traders and real traders, most model parameters can be calibrated by looking at their empirical counterpart. In section 3.2 we have seen that results show a higher sensitivity with respect to the parameters associated to the technical strategy than to the fundamentalist strategy or the noise used in price or fundamental value formation process. It is thus specially important to accurately calibrate these parameters, but the realism with which we have implemented this strategy greatly facilitates the task. The entry and exit rules employed by technical agents are the same than used by real traders, and we can get information on which parameter values are usually employed in real markets by turning again to practitioners literature.

Table 2 summarises the value of all the model parameters used in the results described in the rest of sections. Next, we describe how these values have been determined.

- Parameters associated to price formation: The impact of traders in price formation is normalised with the liquidity parameter $\lambda$, so this parameter is linked to the number of agents (the higher the trader population size, the higher the liquidity). Although this parameter has an empirical interpretation, its value is not observable, and it has then been calibrated by looking at the face validity of simulation outputs (e.g. a small value of liquidity can result in diverging price patterns) and the stylised facts replicated by the model.

The random term in price formation (see formula ( 1 )) is governed by the standard deviation parameter $\sigma_{P}$, whose value has been set to obtain an overall price volatility value in line with empirical daily volatility of S\&P500 in the last years (assuming here that one time step is equivalent to one trading day).

- Parameters associated to fundamental value formation: The fundamental value process depends on the standard deviation term $\sigma_{V}$. As seen in section 3.2, model outputs are not sensitive to this parameter, and its value has been set by looking at the face validity of simulation outputs.

- Parameters associated to the fundamentalist strategy: Although we do not have empirical evidence on which thresholds are used by fundamentalist traders, we have used plausible values for the mispricing level required to enter and exit a position $\left(T^{f}\right.$, $\tau^{f}$ ), and we have fine-tuned these values - together with the unobservable parameter $v^{f}$ - by looking at the stylised facts replicated by the model.

- Parameters associated to the technical strategy: These are the parameters which need a finer calibration because they have a more noticeable impact on simulation results. To implement the technical trading strategy, we have built on techniques widely used in real markets, and so when it came to setting the values of the different windows we 
turned to the practitioner literature. The windows for the short- and long-term moving averages $\left(w_{S}^{t r}, w_{L}^{t r}\right)$ move around 10 and 40 as these are the values usually employed by real technical investors (Kestner, 2003); the window for the exit channel moves around 20 as this is the typical period (Milton, 2016).

\begin{tabular}{|c|c|c|}
\hline Parameter & Value & Parameter description \\
\hline$N_{\text {ticks }}$ & 2000 & Number of ticks of each run \\
\hline$\lambda$ & 400 & Liquidity \\
\hline$P_{0}$ & 100 & Initial price \\
\hline$\sigma_{P}$ & 0.4 & Standard deviation for random term in price formation \\
\hline$N_{F U N D}$ & 200 & Number of fundamentalist traders \\
\hline$N_{\text {TREND }}$ & 200 & Number of technical traders \\
\hline$\sigma_{V}$ & 0.25 & $\begin{array}{l}\text { Standard deviation for random term in fundamental value } \\
\text { formation }\end{array}$ \\
\hline$\left[v_{\min }, v_{\max }\right]$ & {$[-8,8]$} & $\begin{array}{l}\text { Boundaries of the uniform distribution that sets the } \\
\text { difference between the fundamental value and the value } \\
\text { perceived by each fundamentalist trader }\end{array}$ \\
\hline$\left[T_{\min }, T_{\max }\right]$ & {$[2,5]$} & $\begin{array}{l}\text { Boundaries of the uniform distribution that sets the entry } \\
\text { thresholds of fundamentalist traders }\end{array}$ \\
\hline$\left[\tau_{\min }, \tau_{\max }\right]$ & {$[-0.5,1]$} & $\begin{array}{l}\text { Boundaries of the uniform distribution that sets the exit } \\
\text { thresholds of fundamentalist traders }\end{array}$ \\
\hline$\left[w_{S, \min }^{t r}, w_{S, \max }^{t r}\right]$ & {$[5,15]$} & $\begin{array}{l}\text { Boundaries of the uniform distribution that sets the } \\
\text { window of short-term moving average used by technical } \\
\text { traders }\end{array}$ \\
\hline$\left[w_{L, \min }^{t r}, w_{L, \max }^{t r}\right]$ & {$[35,50]$} & $\begin{array}{l}\text { Boundaries of the uniform distribution that sets the } \\
\text { window of long-term moving average used by technical } \\
\text { traders }\end{array}$ \\
\hline$\left[w_{C, \min }^{t r}, w_{C, \max }^{t r}\right]$ & {$[5,30]$} & $\begin{array}{l}\text { Boundaries of the uniform distribution that sets the } \\
\text { window of exit channel used by technical traders }\end{array}$ \\
\hline
\end{tabular}

Table 2 - Table of parameters used in the simulations

\subsection{Output validation}

The application of computational methods to the rich collection of financial data has allowed to identify different statistical regularities that repeatedly appear in many different markets and at different times ( (Giardina \& Bouchaud, 2003), (Taylor S. , 2005)). These statistical regularities - known as stylised facts - are often used to assess the validity of financial market models, 
including agent-based models: the better a model reproduces one or more of these stylised facts, the more valid the model is.

The models reviewed in section 1.3 reproduce some of the statistical properties repeatedly observed in financial markets, but there is no model capable of reproducing all the stylised facts. Our model is not an exception: it replicates some of these stylised facts but not all of them. Given the simplicity of our model, we can deduce that the mechanism leading to these properties is the interaction between the fundamentalist and technical agents: fundamentalist traders induce a dynamic similar to that of a random walk (which is linked to properties such as the lack of return autocorrelations or the unit roots), but technical traders induce correlations in price movements (which are linked to properties such as volatility clustering). The interaction of both groups allows to replicate in a greater or lesser degree some of the stylised facts of stock markets.

We will study next to what extent our artificial market satisfies the main stylised facts, in order to evaluate the output validity of the model. As in section 3.1, average results are based on 200 runs.

Lack of return autocorrelation. The autocorrelations of the time series of asset returns are usually insignificant, except for very small time scales (Slanina, 2014). This indicates that it is not possible to know if the price of an asset will rise or fall in the next period (Cristelli, 2014), which is consistent with the efficient market hypothesis.

In Figure 22 we present the average autocorrelation function of the return series obtained from our simulations. We can see that the autocorrelations tend to 0 when the lag increases, although this decay is not as quick as observed in real markets.

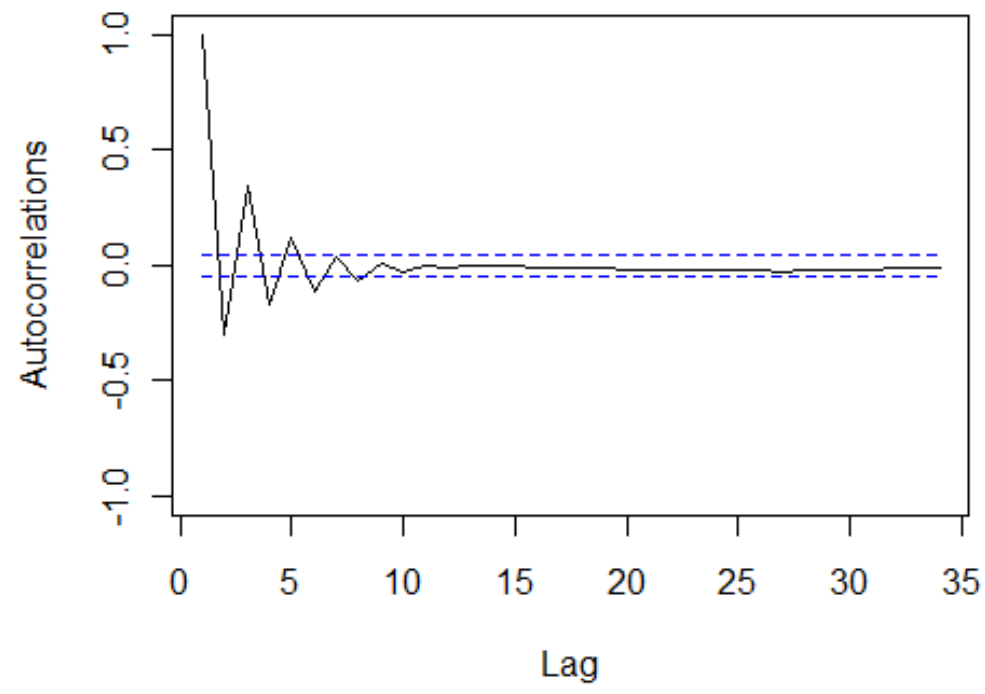

Figure 22 - Average autocorrelations of returns over 200 runs

Fat tails. Financial returns are commonly modelled with a normal distribution due to its simplicity, but the empirical distribution of returns does not adjust to a Gaussian bell, as it is more peaked and has more probability mass in the tails (Cont, 2001). The presence of fat tails 
implies that the price of an asset suffers extreme booms and busts more often than predicted by a normal distribution.

As in real markets, the distribution of the return series obtained with our model is more leptokurtic than the normal distribution. The histogram of returns (Figure 23) has more mass in the center and the tails than a normal distribution with the same mean and variance (bell curve). Further evidence of fat tails is observed in the QQ-plot of the return distribution (Figure 24), which moves away from the diagonal - corresponding to a normal distribution - in the queues. Furthermore, the mean of excess kurtosis, which measures the size of the probability in the queues (Tsay, 2005) is 0.57 (with values comprised between 0.13 and 1.1), what indicates again that the distribution of returns is leptokurtic.

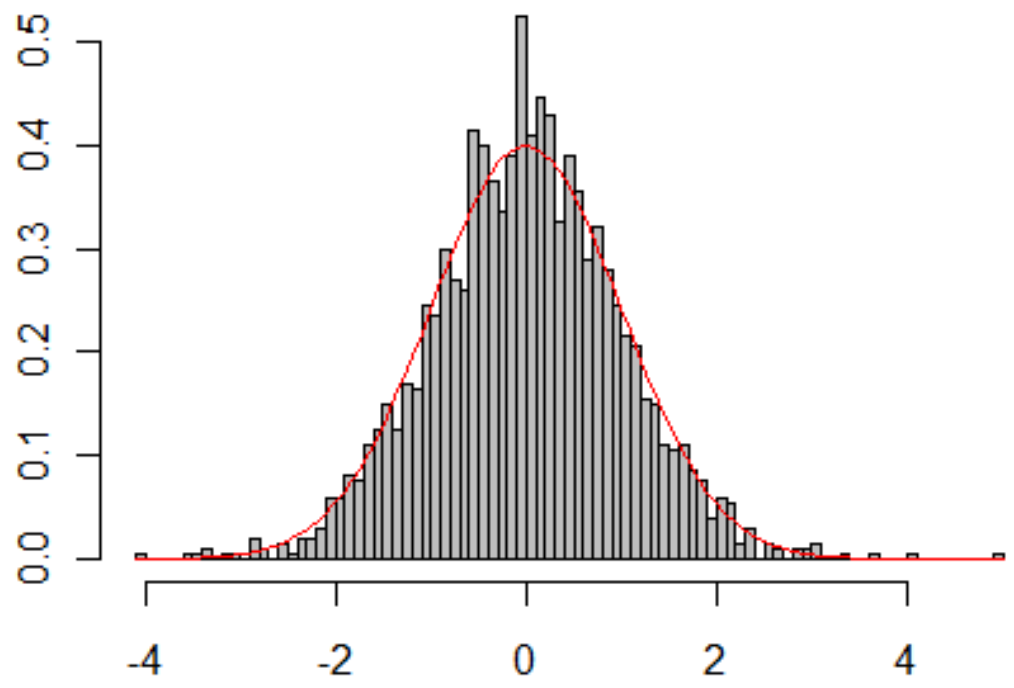

Figure 23 - Histogram of return distribution for a single run

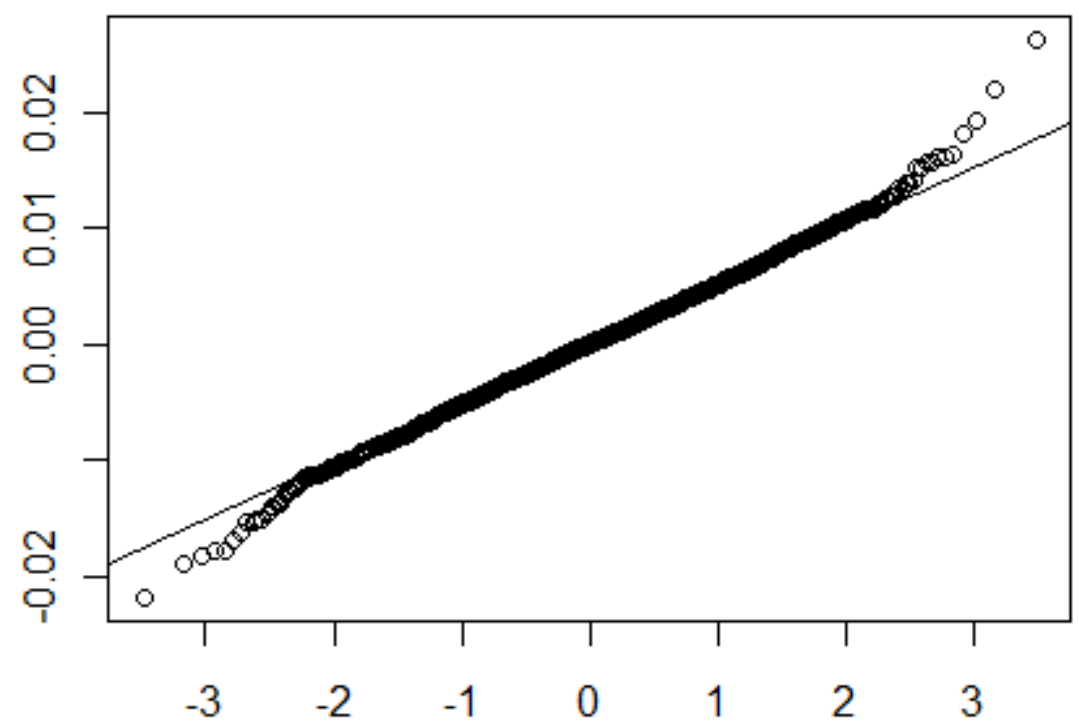

Figure 24-QQ plot of return distribution for a single run 
Volatility clustering. Although returns are not autocorrelated, further analysis reveals that they are not independent, either (Slanina, 2014): the absolute value or the square of returns exhibit significant autocorrelation over days or even weeks for a variety of stocks and indices (Cont, 2001). This implies that big price changes are usually followed by big changes (of any sign), and small changes are usually followed by small changes (Chakraborti, Toke, Patriarca, \& Abergel, 2011). When plotting the autocorrelation function of volatility - where volatility can be estimated both as the absolute value or the square of returns - we can see that it remains positive for several lags (Figure 25), but decays to 0 faster than in real markets.
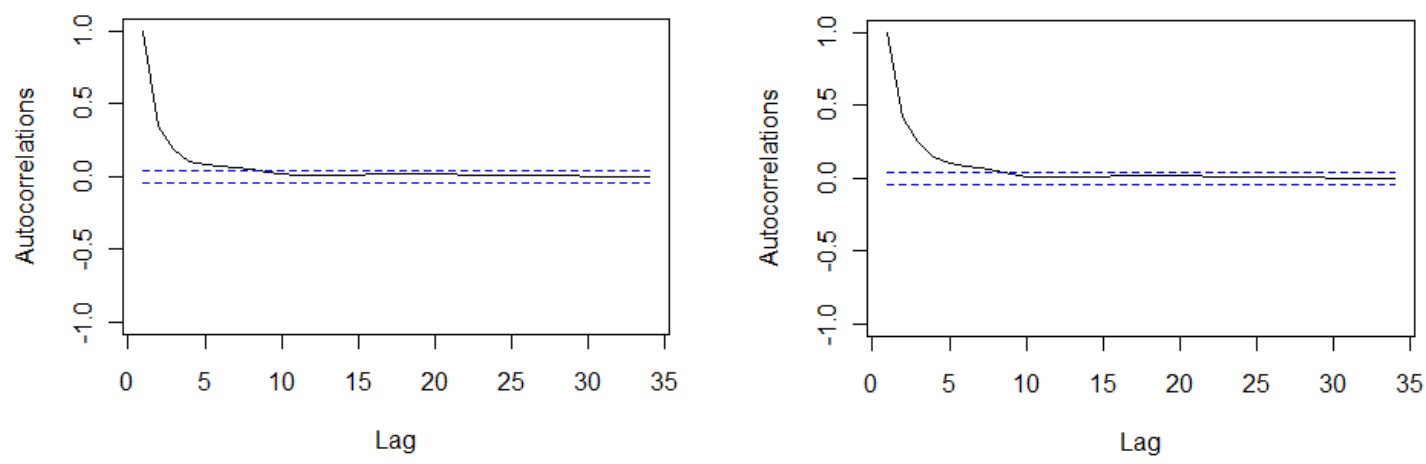

Figure 25 - Average autocorrelation of absolute value (left) and square (right) of returns over 200 runs

Although the autocorrelation function of volatility (Figure 25) seems to decay to 0 at the same rate that the autocorrelation function of returns (Figure 22), when studying the long-term memory of both series we can observe a different internal structure. Their Hurst exponent ${ }^{6}$ reveals that the absolute value or the squared returns have longer-term memory: the average Hurst exponent of volatility is $H=0.72$ for the absolute value of returns and $H=0.77$ for the square of returns, what indicates that these series have long-term memory, whereas the average Hurst exponent for the returns is close to $0.5(H=0.53)$, what indicates that this series has no long-term memory. Even though these values are consistent with the Hurst values observed empirically, it should be noted that it is difficult to accurately measure the Hurst exponent, specially if the series is affected by noise (Clegg, 2006). Therefore, the values shown here for the Hurst exponent ${ }^{7}$ should be taken with some caution. Having said this, it is anyway interesting to observe that the volatility series invariably has a greater exponent than the return series - an indication that its persistence or long-term memory is higher.

\footnotetext{
${ }^{6}$ When the decay of the autocorrelation function of a process follows a power law with exponent $\beta<1$, the process is said to have long-term memory (Bouchaud, Farmer, \& Lillo, 2009), implying that events that occurred long ago still have an impact on the current values (Thompson, 2011). The Hurst exponent can be used to find out if a process has long-term memory, and is calculated as $H=1-\frac{\beta}{2}$ (Rickles, 2011). A process with long-term memory is characterised by having a Hurst exponent $H \in(0.5,1)$ (empirical studies have found values $H \in(0.7,0.9)$ for equity markets ( (Oh, Kim, \& Eom, 2006), (Yang, Wang, \& $\mathrm{Hu}, 2013)$ ). The exponent of a process with short-term memory (such as the series of returns) is $H=0.5$, and its autocorrelation function decays faster (Bouchaud, Farmer, \& Lillo, 2009).

${ }^{7}$ The Hurst exponent reported here has been calculated with the 'hurstSpec' function of the 'fractal' package of R. There are several functions available in R to calculate the Hurst exponent, and 'hurstSpec' has been reported to be the most accurate one (Stroe-Kunold, Stadnytska, Werner, \& Braun, 2009).
} 
All these analyses reveal that it is not clear whether our model reproduces the clustering of volatility: if we only based on the autocorrelation function, we would say that the model does not replicate this property because the decay is faster than observed in real markets, but when analysing the long-term memory of the volatility series we can see that it has an underlying structure different from the return series and displays long-term dependence as the empirical volatility.

Correlation between volume and volatility. The correlation between trading volume (calculated as the sum of orders issued by all the agents in absolute value) and volatility is positive, as observed in real markets (Cont, 2001). Figure 26 shows the range of values of correlation between volume and absolute value of returns, which moves between 0.57 and 0.70 .

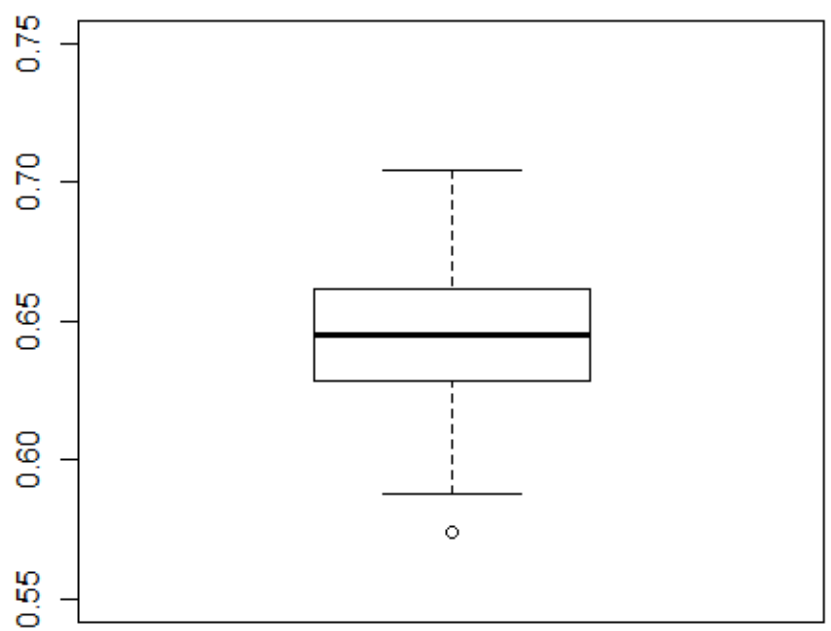

Figure 26 - Boxplot of the correlation between volume and volatility over 200 runs

Unit root. It cannot be statistically rejected that the series of stock prices follows a random walk (which is a particular case of an AR(1) process with a unit root (Tsay, 2005)), consistently with the efficient market hypothesis. The Dickey-Fuller test (see (Taylor S. , 2005) for a description of the test) is the standard tool to detect whether an AR (1) process is a random walk, and when applied to the time series of real or logarithmic prices of an asset usually cannot reject the null hypothesis (Lux \& Marchesi, 2000).

When running the augmented Dickey-Fuller test with the time series of log-prices obtained from simulations, the null hypothesis is accepted in $76 \%$ of runs, an indication that the unit root property is satisfied in most simulations.

Leverage effect. The correlation between returns and future volatility of an asset is negative and decays slowly to 0 (Cont, 2001). This effect indicates that price movements have an asymmetric impact on volatility: when the price falls (i.e., when the return is negative), then the volatility increases, whereas if the price goes up (i.e., when the return is positive), then the volatility is reduced (Dudukovic, 2013). However, the inverse relationship is not satisfied: the correlation between volatility and future returns is nearly negligible (Cont, 2001).

The plot of the cross-correlation function between the series of returns and past or future volatility (Figure 27) reveals that the model does not satisfy the leverage effect, since the two 
series have no significant correlations for any lag. In fact, in the case that the two series were correlated, the leverage effect could not be satisfied, since the behaviour of our model is perfectly symmetrical for both a price increase or a decrease.

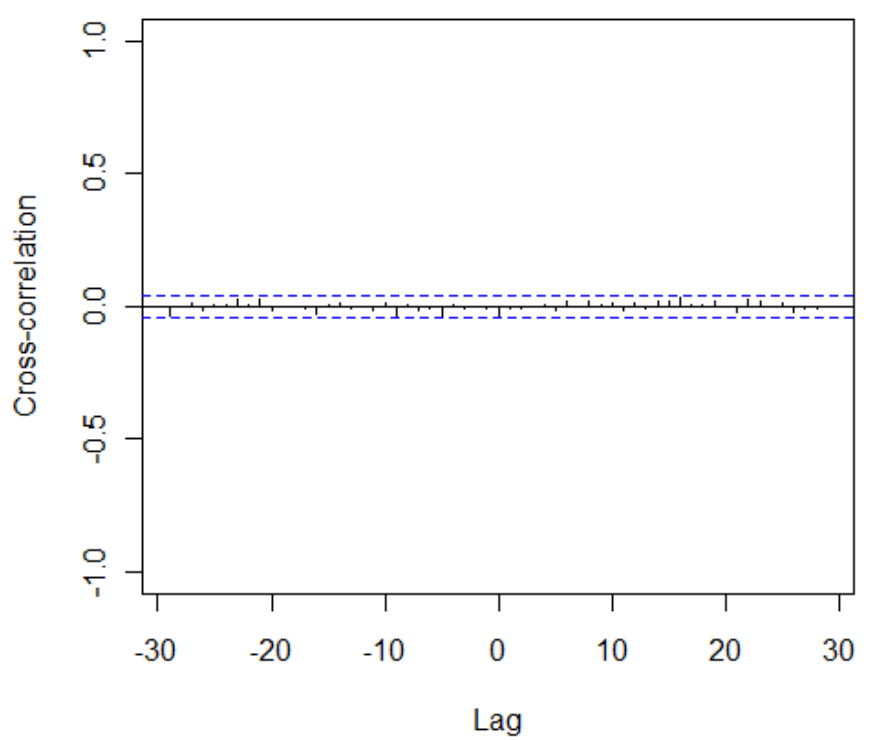

Figure 27 - Cross-correlation function between the series of volatility and returns for a single run

Taylor effect. The autocorrelations of the absolute value of returns are usually higher than those obtained with the squared returns (Cont, 2001). More generally, the autocorrelation of the series $\left|r_{t}\right|^{d}$ reaches a maximum when $d$ is around 1 (Ding, Granger, \& Engle, 1993).

To study if our model exhibits the Taylor effect we include in Figure 28 the graph of the autocorrelation function of $\left|r_{t}\right|^{d}$ as a function of $d$ for different lags. The Taylor effect is satisfied when these curves reach their maximum value around $d=1$ (marked with a vertical dashed line). As illustrated in Figure 28, the Taylor effect is not met, because the maximum autocorrelation for some lags is achieved in $d=2$ or even $d=3$. 


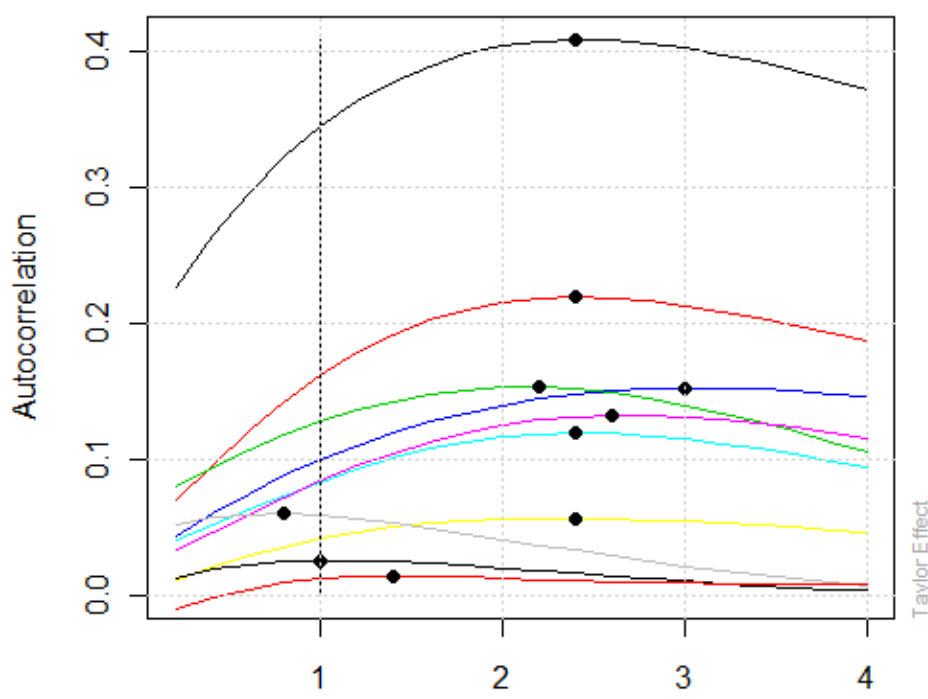

Figure 28 - Taylor effect: autocorrelation function of $\left|r_{t}\right|^{d}$ as a function of $d$ for a single run

Volume autocorrelation. The empirical time series of volume (number of shares purchased and sold during a time interval) is autocorrelated (Covrig \& $\mathrm{Ng}, 2004)$ - as happens with the time series of volatility - and has long-term memory (Rossi \& Santucci de Magistris, 2013).

The autocorrelation function of the volume series obtained from simulations remains positive for several lags and decays slowly to 0, as shown in Figure 29. Moreover, the Hurst exponent proves that the series of volume has long-term memory (its average value is $H=0.93$ ).

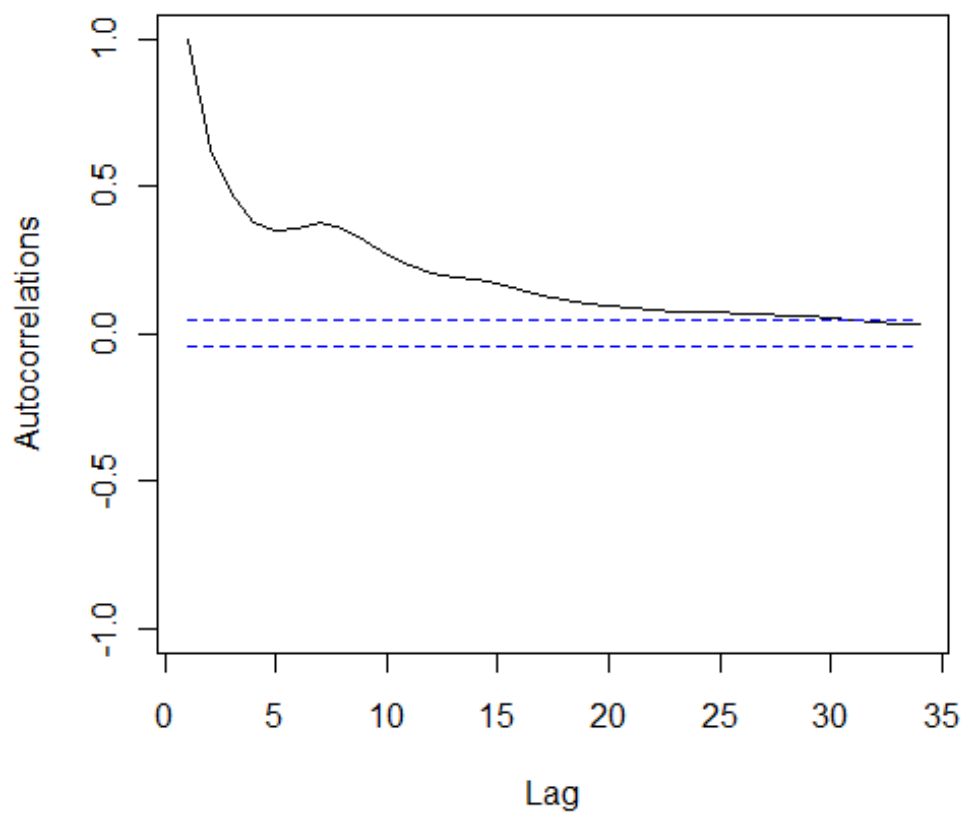

Figure 29 - Average autocorrelation of volume over 200 runs

Volatility skewness. The distribution of volatility (absolute or squared returns) is very asymmetric, with higher frequency of large values than a normal distribution (Sinclair, 2013). In fact, the distribution of volatility fits to a log-normal, although the tails seem to follow a power law (Slanina, 2014). 
The histogram of the absolute value of resulting returns (Figure 30) reveals that the distribution is asymmetrical, with the bulk of observations lying on the right as observed in real markets. The skewness is positive in all the runs (its mean value is 1.3), what indicates that the left tail has a greater mass than the right one.

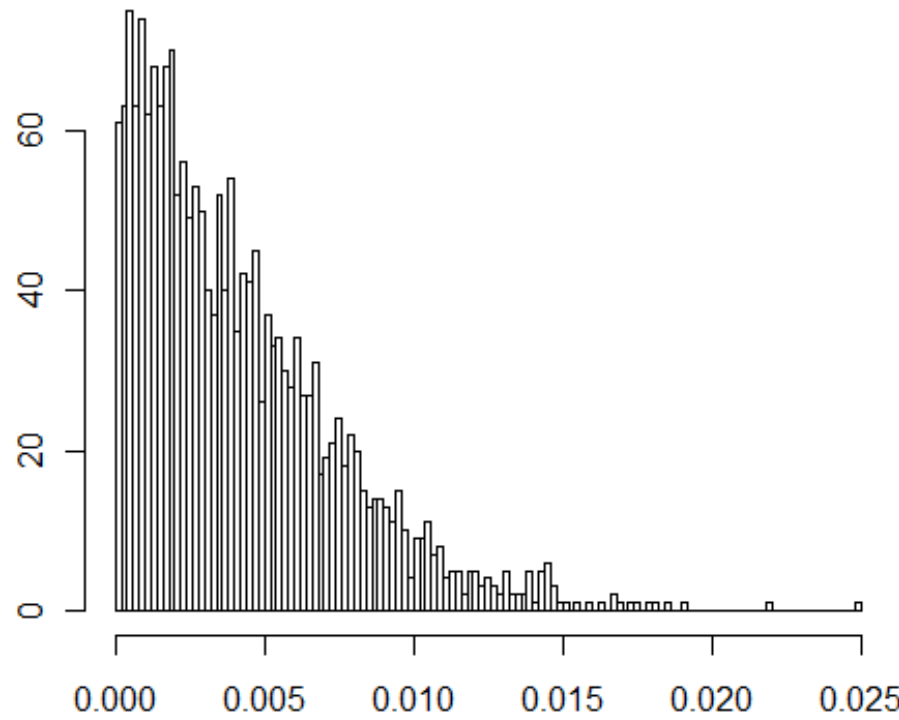

Figure 30 - Histogram of volatility distribution for a single run

Summary. We summarise next in a graphical way which stylised facts are reproduced by our model. We can observe that the model does not perfectly replicate the whole set of stylised facts. In this regard, it is in line with the other agent-based models of financial markets available in the literature, as there is no model that is able to reproduce all statistical properties listed in Table 3.

\begin{tabular}{|l|l|c|}
\hline \multicolumn{1}{|c|}{ Stylised fact } & \multicolumn{1}{|c|}{ Test/Analysis } & $\begin{array}{c}\text { Is the test } \\
\text { satisfied? }\end{array}$ \\
\hline \hline \multirow{2}{*}{$\begin{array}{l}\text { Lack of return } \\
\text { autocorrelation }\end{array}$} & Autocorrelation plot & Partially \\
\cline { 2 - 3 } & Hurst exponent & Yes \\
\hline \multirow{2}{*}{ Fat tails } & Histogram & Yes \\
\cline { 2 - 3 } & QQ plot & Yes \\
\cline { 2 - 3 } & Excess kurtosis & Yes \\
\hline Volatility clustering & Autocorrelation plot & Yes \\
\cline { 2 - 4 } & Hurst exponent & Yes \\
\hline $\begin{array}{l}\text { Correlation volume- } \\
\text { volatility }\end{array}$ & $\begin{array}{l}\text { Correlation between volume and } \\
\text { volatility }\end{array}$ & Yes \\
\hline Unit root & Dickey-Fuller test & No \\
\hline Leverage effect & Cross-correlation betwen returns & Pally \\
\hline
\end{tabular}




\begin{tabular}{|l|l|c|}
\hline & and volatility & \\
\hline Taylor effect & Taylor plot & No \\
\hline Volume autocorrelation & Autocorrelation plot & Yes \\
\cline { 2 - 3 } & Hurst exponent & Yes \\
\hline \multirow{2}{*}{ Volatility skewness } & Histogram & Yes \\
\cline { 2 - 3 } & Skewness & Yes \\
\hline
\end{tabular}

Table 3 - Graphical summary of stylised facts satisfied by the model

\section{Conclusions}

In this article we have presented an agent-based model of a stock market populated by fundamentalist and technical traders, which are the most popular trading approaches in financial markets. The implementation of this model has allowed us to reflect on some aspects related to the validation and calibration of agent-based models.

Instead of building the model from scratch, we have replicated the model of Farmer and Joshi (2002), which is one of the most relevant and well-known agent-based model of financial markets. This model-to-model exercise - also considered a type of validation by some authors has allowed us to detect a recurring behaviour against common sense in the FJ model: the technical strategy never makes any profit, and this situation is non-sensible given that a lossmaking strategy would soon disappear from real markets.

In our review of agent-based models of financial markets we have realised that this type of obvious behaviours are seldom checked, so one runs the risk of having models which are valid according to the usual criteria but not sensible. For this reason, we have argued that it is also necessary to look at common-sense evidence and incorporate it into models, instead of only looking at the statistical stylised facts as usually done in artificial markets.

Following this line of argumentation, we have modified the FJ model by implementing a new technical strategy that is competitive. To do so, we have turned to the practitioners literature and reproduced one of the most widely used technical strategies. Here lies another contribution of this paper: we advocate for the implementation of agent behaviours close to the real ones, as this greatly facilitates the calibration of the model and the interpretation of results. We are aware that the feasibility of this task depends on the subject area: in the financial arena, many traders use mechanistic rules which can be seamlessly translated to coded agent rules. However, in other areas it can be more difficult to achieve such a level of homeomorphism between artificial and real behaviour; even in this case, we encourage the modelling of realistic agent behaviours, either by drawing on relevant literature as done in this paper or by directly involving stakeholders (as done for example under the companion modelling approach (Barreteau, Bousquet, Étienne, Souchère, \& d'Aquino, 2014)).

After building the model, we have validated it in an extensive way. The usual practice in agentbased models of financial markets is to validate the simulation outputs comparing them with a 
set of statistical stylised facts. Here, we have used an extended validation procedure consisting of four steps - face validation, sensitivity analysis, calibration and output validation - which has allowed us to provide a more comprehensive assessment of the model validity. It would be beneficial to generalise the adoption of an extended validation method as the one used here as this would provide valuable information on some aspects which are usually neglected, such as the sensitivity of the model to its parameters, or the calibration method.

The stock market model presented here is a first step in the construction of a more ambitious agent-based model. The work described in this paper ensures that our fundamentalist+technical model is a realistic, sensible and valid testbed with which to test the effect of other market mechanisms, such as the inclusion of risk management practices (work reported elsewhere).

\section{Acknowledgements}

We would like to thank the anonymous reviewers for their insightful and constructive comments.

\section{References}

Adrian, T., \& Boyarchenko, N. (2012). Intermediary leverage cycles and financial stability. New York: Federal Reserve Bank of New York - Staff report No. 567.

Adrian, T., \& Shin, H. (2013). Procyclical Leverage and Value-at-Risk. New York: Federal Reserve Bank of New York Staff Reports, No. 338.

Alfarano, S., Lux, T., \& Wagner, F. (2005). Estimation of agent-based models: The case of an asymmetric herding model. Computational Economics, 26, 19-49.

Arthur, W., Holland, J., LeBaron, B., Palmer, R., \& Tayler, P. (1996). Asset pricing under endogenous expectations in an artificial stock market. SFI Working Paper, 96-12-093.

Aymanns, C., \& Farmer, J. (2015). The dynamics of the leverage cycle. Journal of Economic Dynamics and Control, 50, 155-179.

Aymanns, C., Caccioli, F., Farmer, J., \& Tan, V. (2016). Taming the Basel leverage cycle. Journal of Financial Stability, 27, 263-277.

Balci, O. (1995). Principles and techniques of simulation validation, verification, and testing.

Proceedings of the 1995 Winter Simulation Conference, (pp. 147-154).

Bank of England. (2004). Financial stability review - December 2004. Bank of England.

Barreteau, O., Bousquet, F., Étienne, M., Souchère, V., \& d'Aquino, P. (2014). Companion modelling: A method of adaptive and participatory research. In M. Étienne, Companion modelling (pp. 13-40). Éditions Quae. 
Beck, T., De Jonghe, O., \& Schepens, G. (2011, July 25). Bank competition and stability: Cross-country heterogeneity. Retrieved June 14, 2013, from VOX CEPR's Policy Portal: http://www.voxeu.org/article/bank-competition-and-stability-cross-countryheterogeneity

Bianchi, C., Cirillo, P., Gallegati, M., \& Vagliasindi, P. (2007). Validating and calibrating agent-based models: A case study. Computational Economics, 30, 245-264.

BIS. (1999). A review of financial markets events in autumn 1998. Basilea: Bank for International Settlements.

Bonenkamp, U. (2010). Combining technical and fundamental trading strategies. Heidelberg: Gabler.

Bookstaber, R. (2012). Using agent-based models for analyzing threats to financial stability. Office of Financial Research.

Bookstaber, R., Cetina, J., Feldberg, G., Flood, M., \& Glasserman, P. (2013). Stress tests to promote financial stability: Assessing progress and looking to the future. Office of Financial Research - Working paper 0010.

Bouchaud, P., Farmer, J., \& Lillo, F. (2009). How markets slowly digest changes in supply and demand. In T. Hens, \& K. Schenk-Hoppé, Handbook of financial markets: Dynamics and evolution (pp. 57-160). Amsterdam: North Holland - Elsevier.

Brock, W., \& Hommes, C. (1998). Heterogeneous beliefs and routes to chaos in a simple asset pricing model. Journal of Economic Dynamics and Control, 1235-1274.

Brunnermeier, M., \& Pedersen, L. (2009). Market liquidity and funding liquidity. The Review of Financial Studies, 22(6), 2201-2238.

Carley, K. (1996). Validating Computational Models.

Chakraborti, A., Toke, I., Patriarca, M., \& Abergel, F. (2011). Econophysics review: I. Empirical facts. Quantitative finance, 11(7), 991-1012.

Chen, S., \& Yeh, C. (2001). Evolving traders and the business school with genetic programming: A new architecture of the agent-based artificial stock market. Journal of Economic Dynamics and Control, 25, 363-393.

Choudhry, M. (2006). An introduction to value-at-risk. Chichester: John Wiley \& Sons.

Clegg, R. (2006). A practical guide to measuring the Hurst parameter. 21st UK Performance Engineering Workshop, School of Computing Science Technical Report Series, CSTR916, (pp. 43-55). Newcastle.

Colander, D. (2009). Testimony submitted to the U.S. House of Representatives, Committee on Science and Technology, for the hearing "The risks of financial modeling: VaR and the economic meltdown".

Cont, R. (2001). Empirical properties of asset returns: stylized facts and statistical issues.

Quantitative finance, 1, 223-236. 
Covrig, V., \& Ng, L. (2004). Volume autocorrelation, information, and investor trading. Journal of Banking and Finance, 28, 2155-2174.

Cristelli, M. (2014). Complexity in financial markets. Springer.

Danielsson, J., \& Shin, H. (2002). Endogenous risk. http://www.riskresearch.org/files/DanielssonShin2002.pdf.

Danielsson, J., Embrechts, P., Goodhart, P., Keating, C., Muennich, F., Renault, O., et al. (2001). An academic response to Basel II. LSE Financial Markets Group.

Danielsson, J., Shin, H., \& Zigrand, J. (2004). The impact of risk regulation on price dynamics. Journal of Banking \& Finance, 28(1069-1087).

Danielsson, J., Shin, H., \& Zigrand, J. (2009). Risk appetite and endogenous risk.

Davis, E. (1999). A reappraisal of market liquidity risk in the light of the Russia/LTCM global securities market crisis. Workshop on "Empirical research on bank supervision and structure". Amsterdam: Basle Committee on Banking Supervision.

De Grauwe, P., \& Grimaldi, M. (2004). Bubbles and crashes in a behavioural finance model. Sveriges Riksbank working paper series No.164.

Ding, Z., Granger, C., \& Engle, R. (1993). A long memory property of stock market returns and a new model. Journal of Empirical Finance, 1, 83-106.

Dosi, G., Fagiolo, G., \& Roventini, A. (2006). An evolutionary model of endogenous business cycles. Computational Economics, 27, 3-34.

Dudukovic, S. (2013). Capturing stylized facts of stock market volatility and higher order cumulant function. Cambridge Business \& Economics Conference (CBEC). Cambridge.

Duffy, J., \& Ünver, U. (2006). Asset price bubbles and crashes with near-zero-intelligence traders. Economic Theory, 537-563.

ECB. (2007). Financial stability review - June 2007. Frankfurt: European Central Bank.

Edmonds, B., \& Moss, S. (2005). From KISS to KIDS - An 'Anti-simplistic' Modelling Approach. In P. Davidsson, B. Logan, \& K. Takadama, Multi-Agent and Multi-AgentBased Simulation (Vol. 34, pp. 130-144). Springer.

Einarsson, R. (2013). Reproducing the stylized facts of financial returns. Göteborg: Chalmers University of Technology.

Fabretti, A. (2013). On the problem of calibrating an agent based model for financial markets. Journal of Economic Interaction and Coordination, 8, 277-293.

Fagiolo, G., Moneta, A., \& Windrum, P. (2007). A critical guide to empirical validation of agent-based models in economics: Methodologies, procedures, and open problems. Computational Economics, 30, 195-226.

Fagiolo, G., Windrum, P., \& Moneta, A. (2006). Empirical validation of agent-based models: A Critical survey. Pisa: LEM Working Paper2006/14. 
Faria, L. (2012). Financial regulation - part II: Bank's behaviour under Basel III capital requirements using an agent-based model. Policy paper 12/19.

Faria, L., \& Phelps, S. (2011). An investigation of the consequences of Basel III using an agentbased model. The 13th International Conference on Electronic Commerce. Liverpool.

Farmer, J., \& Joshi, S. (2002). The price dynamics of common trading strategies. Journal of Economic Behavior and Organization, 49, 149-171.

Feng, L., Li, B., Podobnik, B., Preis, T., \& Stanley, E. (2012). Linking agent-based models and stochastic models of financial markets. PNAS, 109(22), 8388-8393.

Feridun, M. (2005). Failure of value at risk systems: A case study. European Journal of Economics, Finance and Administrative Sciences, 2(1), 57-67.

Finger, C. (2009). VaR is from Mars, Capital is from Venus. RiskMetrics Group - Research monthly April 2009.

Fostel, A., \& Geanakoplos, J. (2008). Leverage cycles and the anxious economy. New Haven: Cowles Foundation Paper No.1233.

Frenken, K. (2005). History, state and prospects of evolutionary models of technical change: a review with special emphasis on complexity theory. Utrecht University.

Gadanecz, B., \& Jayaram, K. (2008). Measures of financial stability - A review. IFC Bulletin No. 31 .

Geanakoplos, J. (1997). Promises promises. New Haven: Cowles Foundation Paper N.1057.

Geanakoplos, J. (2003). Liquidity, Default, and Crashes: Endogenous Contracts in General Equilibrium. In Advances in Economics and Econometrics: Theory and Application (pp. 170-205). New York: Cambridge University Press.

Geanakoplos, J. (2009). The leverage cycle. En D. Acemoglu, K. Rogoff, \& M. Woodford, NBER Macroeconomics Annual 2009 (págs. 1-65). University of Chicago Press.

Giardina, I., \& Bouchaud, J. (2003). Volatility clustering in agent based market model. In M. Gallegati, A. Kirman, \& M. Marsili, The complex dynamics of economic interaction (pp. 171-196). Berlin: Springer.

Gilbert, N. (2004). Open problems in using agent-based models in industrial and labor dynamics. In R. Leombruni, \& M. Richiardi, Industry and Labor Dynamics: the agentbased computational approach (pp. 401-405). World Scientific.

Gilli, M., \& Winker, P. (2003). A global optimization heuristic for estimating agent based models. Computational Statistics and Data Analysis, 42, 299-312.

Haldane, A., \& May, R. (2011). Systemic risk in banking ecosystems. Nature, 469, 351-355.

Hales, D., Rouchier, J., \& Edmonds, B. (2003). Model-to-model analysis. Journal of Artificial Societies and Social Simulation, 6(4).

Hermsen, O. (2010). Does Basel II destabilize financial markets? An agent-based financial market perspective. The European Physical Journal B, 73, 29-40. 
Hoelle, M. (2016). The effects of dependent beliefs on endogenous leverage.

Hommes, C. (2006). Heterogeneous agent models in economics and finance. In K. Tesfatsion, \& K. Judd, Handbook of Computational Economics, Vol. 2 (pp. 1109-1186).

Amsterdam: North Holland - Elsevier.

IMF. (2007). Global financial stability report - October 2007. Washington D.C.: International Monetary Fund.

Janssen, M., \& Ostrom, E. (2006). Empirically Based, Agent-based models. Ecology and Society, 11(2), 37.

Johnson, N., Jefferies, P., \& Ming Hui, P. (2003). Financial market complexity. New York: Oxford University Press.

Jorion, P. (2001). Value at risk: The new benchmark for managing financial risk. New York: McGraw-Hill.

Jorion, P. (2002). Fallacies about the effects of market risk management systems. Financial Stability Review - December 2002, 115-127.

Kahneman, D., \& Tversky, A. (1979). Prospect theory: An analysis of decisions under risk. Econometrica, 47, 313-327.

Kestner, L. (2003). Quantitative trading strategies. New York: McGraw-Hill.

Klügl, F. (2008). A validation methodology for agent-based simulations. SAC'08. Fortaleza, Brazil.

LeBaron, B. (2006). Agent-based computational finance. In L. Tesfatsion, \& K. Judd, Handbook of Computational Economics, Vol. 2 (pp. 1188-1233). Amsterdam: North Holland - Elsevier.

LeBaron, B., \& Yamamoto, R. (2007). Long-memory in an order-driven market. Physica A, $383,85-89$.

LeBaron, B., Arthur, W., \& Palmer, R. (1999). Time series properties of an artificial stock market. Journal of Economic Dynamics \& Control, 23, 1487-1516.

LiCalzi, M., \& Pellizzari, P. (2006). Breeds of risk-adjusted fundamentalist strategies in an order-driven market. Physica A, 359, 619-633.

Llacay, B. (2015). El impacto de las técnicas VaR en los mercados financieros. Enfoque basado en la simulación multiagente. $\mathrm{PhD}$ Thesis, Universitat de Barcelona.

Lux, T. (1995). Herd behaviour, bubbles and crashes. The Economic Journal, 105(431), 881896.

Lux, T., \& Marchesi, M. (1999). Scaling and criticality in a stochastic multi-agent model of a financial market. Nature, 397, 498-500.

Lux, T., \& Marchesi, M. (2000). Volatility clustering in financial markets: A microsimulation of interacting agents. International Journal of Theoretical and Applied Finance, 3(4), 675702 . 
MacKenzie, D. (2003). Long-Term Capital Management and the Sociology of Arbitrage. Economy and Society, 32, 349-380.

Madhavan, A. (2000). Market microstructure: A survey. Los Angeles: Marshall School of Business.

Malerba, F., Nelson, R., Orsenigo, L., \& Winter, S. (1999). 'History-friendly' models of industry evolution: The computer industry. Industrial and Corporate Change, 8(1), 3-40.

Malkiel, B. (1973). A random walk down Wall Street. New York: Norton.

Malkiel, B. (1973). A random walk down Wall Street. Nueva York: Norton.

Manamperi, N. (2013). A comparative analysis of US financial stress indicators. Lubbock: Texas Tech University.

Martínez-Jaramillo, S., \& Tsang, E. (2009). Evolutionary computation and artificial financial markets. In A. Brabazon, \& M. O'Neill, Natural computing in computational finance (Vol. 2, pp. 137-179). Berlin: Springer.

McNeil, A., Frey, R., \& Embrechts, P. (2005). Quantitative risk management: Concepts, techniques, and tools. Princeton: Princeton University Press.

Menkhoff, L. (2010). The use of technical analysis by fund managers: International evidence. Journal of Banking and Finance, 34, 2573-2586.

Milton, A. (2016, June 3). Day trading with Donchian channels. Retrieved February 20, 2017, from The balance: https://www.thebalance.com/day-trading-with-donchian-channels1031186

Milton, A. (3 de June de 2016). Day trading with Donchian channels. Recuperado el 20 de February de 2017, de The balance: https://www.thebalance.com/day-trading-withdonchian-channels-1031186

Morris, S., \& Shin, H. (2000). Market risk with interdependent choice. Conference on liquidity risk. Frankfurt.

Moss, S. (2008). Alternative approaches to the empirical validation of agent-based models. Journal of Artificial Societies and Social Simulation, 11(1).

Moss, S., \& Edmonds, B. (2005). Sociology and simulation: Statistical and qualitative crossvalidation. American Journal of Sociology, 110(4), 1095-1131.

Murphy, J. (1999). Technical analysis of the financial markets. Paramus: New York Institute of Finance.

Ngo, T., \& See, L. (2012). Calibration and validation of agent-based models of land cover change. In A. Heppenstall, A. Crooks, L. See, \& M. Batty, Agent-based models of geographical systems (pp. 181-197). Dordrecht: Springer.

North, M., \& Macal, C. (2007). Managing business complexity - Discovering strategic solutions with agent-based modeling and simulation. New York: Oxford University Press. 
Oh, G., Kim, S., \& Eom, C. (2006, July 29). Long-term memory and volatility clustering in daily and high-frequency price changes. Retrieved from Arxiv preprint physics/0601174: http://www.long-memory.com/returns/OhUmKim2006.pdf

O'Neill, B. (2011). Fundamentals of the stock market. McGraw-Hill.

Pascual, J., Pajares, J., \& López-Paredes, A. (2006). Explaining the statistical features of the Spanish stock market from the bottom-up. In C. Bruun, Advances in Artificial Economics: The Economy as a Complex Dynamic System (pp. 283-294). Berlin: Springer.

Pericoli, M., \& Sbracia, M. (2010). Crowded trades among hedge funds. Working paper.

Perold, A. (1999). Long-Term Capital Management, L.P. Boston: Harvard Business School Publishing.

Persaud, A. (2000). Sending the herd off the cliff edge: The disturbing interaction between herding and market-sensitive risk management practices. ERisk, 1-6.

Peters, E. (2014). Stable vs. unstable markets: A tale of two states. First Quadrant.

Raberto, M., Cincotti, S., Focardi, S., \& Marchesi, M. (2003). Traders' long-run wealth in an artificial financial market. Computational Economics, 22, 255-272.

Rebonato, R. (2007). Plight of the fortune tellers: Why we need to manage financial risk differently. Princeton: Princeton University Press.

Rickles, D. (2011). Econophysics and the Complexity of Financial Markets. In C. Hooker, Philosophy of complex systems (pp. 531-566). Oxford: North Holland - Elsevier.

Rossi, E., \& Santucci de Magistris, P. (2013). Long memory and tail dependence in trading volume and volatility. Journal of Empirical Finance, 22, 94-112.

Saita, F. (2007). Value at risk and bank capital management. San Diego: Academic Press.

Sargent, R. (1998). Verification and validation of simulation models. Proceedings of the 1998 Winter Simulation Conference, (pp. 121-130).

Shimokawa, T., Suzuki, K., \& Misawa, T. (2007). An agent-based approach to financial stylized facts. Physica A, 379, 207-225.

Shin, H. (2010). Risk and liquidity. Oxford: Oxford University Press.

Sinclair, E. (2013). Volatility trading (Second ed.). Hoboken: John Wiley \& Sons.

Slanina, F. (2014). Essentials of econophysics modelling. Oxford: Oxford University Press.

Stroe-Kunold, E., Stadnytska, T., Werner, J., \& Braun, S. (2009). Estimating long-range dependence in time series: An evaluation of estimators implemented in R. Behavior Research Methods, 41(3), 909-923.

Takahashi, H. (2013). Analyzing the influence of Value at Risk on financial markets through agent-based modeling. International Journal of Knowledge-based and Intelligent Engineering Systems, 17, 257-266. 
Tasca, P., \& Battiston, S. (2012). Market procyclicality and systemic risk. Zurich: ETH Risk Center - Working Paper ETH-RC-12-012.

Taylor, M. (2009). What is sensitivity analysis? What is...? series, 1-8.

Taylor, S. (2005). Asset price dynamics, volatility, and prediction. Princeton: Princeton University Press.

ten Broeke, G., van Voorn, G., \& Ligtenberg, A. (2016). Which Sensitivity Analysis Method Should I Use for My Agent-Based Model? Journal of Artificial Societies and Social Simulation, 19(1).

The World Bank. (2013). Global financial development report - Financial stability. Retrieved May 24, 2013, from Key terms explained: http://go.worldbank.org/EXTW5ZJ4C0

Thompson, S. (2011). The stylised facts of stock price movements. The New Zealand Review of Economics and Finance, 1, 50-77.

Thurner, S. (2011). Systemic financial risk: agent based models to understand the leverage cycle on national scales and its consequences. OECD.

Thurner, S., Farmer, J., \& Geanakoplos, J. (2012). Leverage causes fat tails and clustered volatility. Quantitative Finance, 12(5), 695-707.

Triana, P. (2010, December 1). VaR: The number that killed us. Futures Mag.

Trichet, J. (2011). Intellectual challenges to financial stability analysis in the era of macroprudential oversight. Financial Stability Review No. 15 - Banque de France.

Tsay, R. (2005). Analysis of financial time series (Second ed.). Hoboken: John Wiley \& Sons.

Wei, J., Huang, J., \& Hui, P. (2013). An agent-based model of stock markets incorporating momentum investors. Physica A, 392, 2728-2735.

Werker, C., \& Brenner, T. (2004). Empirical calibration of simulation models. Max Planck Institute, Papers of Economics and Evolution \#0410.

Westerhoff, F. (2009). A simple agent-based financial market model: Direct interactions and comparisons of trading profits. BERG working paper series on government and growth, No.61.

Westerhoff, F. (2010). A simple agent-based financial market model: Direct interactions and comparisons of trading profits. In G. Bischi, C. Chiarella, \& L. Gardini, Nonlinear Dynamics in Economics, Finance and the Social Sciences (pp. 313-332). Berlin: Springer.

Whitehead, C. (2013). Destructive coordination. Cornell Law Review, 96, 323-364.

Windrum, P., Fagiolo, G., \& Moneta, A. (2007). Empirical validation of agent-based models: Alternatives and prospects. Journal of Artificial Societies and Social Simulation, 10(2).

Yang, C., Wang, R., \& Hu, S. (2013). Modeling and analysis of an agent-based model for Chinese stock market. Physics Letters A, 377, 2041-2046.

Zeigler, B. (1985). Theory of modelling and simulation. Krieger: Malabar. 
